OECD Statistics Working Papers 2011/06

\section{Measuring the Stock of Human Capital} for Comparative Analysis: An Application of the Lifetime Income Approach to Selected Countries

\section{Gang Liu}

https://dx.doi.org/10.1787/5kg3h0jnn9r5-en 
Organisation de Coopération et de Développement Économiques

Organisation for Economic Co-operation and Development

10-Oct-2011

STATISTICS DIRECTORATE

English - Or. English

MEASURING THE STOCK OF HUMAN CAPITAL FOR COMPARATIVE ANALYSIS:

AN APPLICATION OF THE LIFETIME INCOME APPROACH TO SELECTED COUNTRIES

STATISTICS DIRECTORATE

WORKING PAPER NO. 41

This paper has been prepared by Gang Liu, OECD Statistics Directorate.

For further information please contact:

Gang Lui

E-mail: gang.liu@oecd.org 


\section{OECD STATISTICS WORKING PAPER SERIES}

The OECD Statistics Working Paper Series - managed by the OECD Statistics Directorate - is designed to make available in a timely fashion and to a wider readership selected studies prepared by OECD staff or by outside consultants working on OECD projects. The papers included are of a technical, methodological or statistical policy nature and relate to statistical work relevant to the Organisation.

The Working Papers are generally available only in their original language - English or French - with a summary in the other. Comments on the papers are welcome and should be communicated to the authors or to the OECD Statistics Directorate, 2 rue André Pascal, 75775 Paris Cedex 16, France.

The opinions expressed in these papers are the sole responsibility of the authors and do not necessarily reflect those of the OECD or of the governments of its Member countries.

This document and any map included herein are without prejudice to the status of or sovereignty over any territory, to the delimitation of international frontiers and boundaries and to the name of any territory, city or area.

\section{http://www.oecd.org/std/research}

(C) OECD/OCDE, 2011

Applications for permission to reproduce or translate all or part of this material should be made to: OECD Publications, 2 rue André-Pascal, 75775 Paris, Cedex 16, France; E-mail: rights@oecd.org 
STD/DOC(2011)6 


\section{ACKNOWLEDGEMENT}

Gang Liu is the leader of the OECD human capital project and an analyst in the Household Statistics and Progress Measurement Division of the OECD Statistics Directorate. The paper has been prepared as part of the work undertaken by the OECD Statistics Directorate on the "Measurement of Well-being and Progress of Societies".

The author is deeply indebted to Marco Mira d'Ercole for his advice and guidance through the course of the project. He also wishes to thank Martine Durand, Paul Schreyer, Barbara Fraumeni, Dale Jorgenson, Romina Boarini, Conal Smith, and Carlotta Balestra for comments and suggestions on previous drafts of this paper, as well as Cengiz Cihan, currently at the Central Bank of The Republic of Turkey, who participated in this project during the period of his secondment at the OECD.

This project on human capital measurement in the OECD Statistics Directorate benefited much from the cooperation of other colleagues at the OECD and beyond. The author is grateful to Karinne Logez, Bo Hansson, Jean Yip and Corrine Heckman, from the Directorate for Education, Pascal Marianna, from the Directorate for Employment, Labour and Social Affairs, as well as Kenny Petersson, Statistics Sweden, for helpful support in data collection.

A progress report of the OECD human capital project was presented at the OECD Committee on Statistics (CSTAT) in June 2010, at the $31^{\text {st }}$ IARIW conference in August 2010, and at seminar "Human Capital: Definition and Measurement" organised by ISTAT in Rome in November 2010. The valuable comments from Patricia Ruggles and other participants in these meetings are gratefully acknowledged.

An executive summary of the paper was discussed at the fifty-ninth plenary session of UNECE Conference of European Statisticians (CES) in June 2011. The latest draft version of this paper reflects comments provided by participants to an internal seminar of the OECD Statistics Directorate and by CSTAT delegates.

Last but not least, the author wishes to express his special thanks to the country correspondents of the OECD Human Capital Consortium who provided information for the countries covered by the project, and offered advices on various issues as well as comments on an earlier draft of this paper. These include: Hui Wei (Australian Bureau of Statistics); Wulong Gu (Statistics Canada); Karin W. S. Blix (Statistics Denmark); Jean-Louis Mercy (Eurostat); Magali Beffy and Mathilde Gaini (INSEE, France); Rafael Diez de Medina (ILO); Dmitri Romanov and Efrat Averbach (Israel Bureau of Statistics); Luisa Picozzi (ISTAT, Italy); Takashi Yoshimoto (Economic and Social Research Institute, Japan); SeongHo Han (Statistics Korea); Jaime Rodriguez Carranza (INEGI, Mexico); Marieke Rensman (Statistics Netherlands); Steinar Todsen (Statistics Norway); Tas Papadopoulos (Statistics New Zealand); Jerzy Auksztol (Central Statistical Office of Poland); Georgeta Istrate (INS Romania); Alfredo Cristóbal (INE, Spain); Richard Jones (Office for National Statistics, the United Kingdom); and Ana Aizcorbe (Bureau of Economic Analysis, the United States). 


\begin{abstract}
This paper summarizes the outcomes of the first phase of the OECD human capital project. In so doing, it shows the feasibility of applying the lifetime income approach to measuring human capital for comparative analysis, both across countries and over time. It also highlights the feasibility of applying the methodology to the categorical data (i.e. by 5-year or 10-year age group) that are typically available within the OECD statistics system, rather than to data by single year of age required by the original JorgensonFraumeni methodology.

The results in this paper indicate that the estimated value of human capital is substantially larger than that of traditional physical capital. Ratios of human capital to GDP are in a range from around eight to over ten across countries, broadly in line with those reported in a number of national studies. The distributions of human capital by age, gender, and education show that men dominate women in terms of their human capital holdings. In addition, people with higher education are better off than those with lower education, and the same is true for younger people compared to their older counterparts, although the detailed patterns vary across countries. Decomposition analysis of changes in the volume of human capital demonstrates that changes in population structure between men and women had little effect on the change of human capital per capita. While in all countries higher educational attainment contributed positively to the change of human capital per capita, this is not always sufficient to offset the negative effect of population ageing; as a result, the volume of human capital per capita appeared to have declined in some countries over the observed period. Finally, sensitivity analysis confirms that estimates of the value of human capital depend on the choice of the two key parameters, i.e. annual real income growth rate and discount rate, while within-country distribution of human capital and trends of the volume of human capital are less sensitive to these assumptions.
\end{abstract}

\title{
RÉSUMÉ
}

Ce document de travail fait la synthèse des résultats de la première phase du projet de l'OCDE consacré au capital humain. Il démontre notamment qu'il est possible d'appliquer l'approche en terme de revenus actualisés le long du cycle de vie à la mesure du capital humain à des fins d'analyse comparative, à la fois entre les pays et dans le temps. Le document souligne également que cette méthodologie peut aussi être appliquée à des données catégoriels (c'est-à-dire par classe d'âge de 5 ou 10 ans), généralement disponibles dans le système statistique de l'OCDE, plutôt qu'aux données continues par âge, requises par la méthode Jorgenson-Fraumeni.

Les résultats présentés dans ce rapport montrent que la valeur estimée du capital humain est bien plus importante que celle du capital physique traditionnel. Le rapport capital humain/sur PIB s'inscrit dans une fourchette comprise entre huit et dix dans les différents pays, ce qui est globalement conforme aux chiffres rapportés par un certain nombre d'études nationales. La répartition du capital humain en fonction de l'âge, du sexe et du niveau d'instruction montre que les hommes surpassent les femmes en termes de stock de capital humain. Par ailleurs, les individus les plus instruits tirent davantage leur épingle du jeu que les personnes moins qualifiées et les jeunes ont un capital humain supérieur à celui des personnes plus âgées, bien que dans le détail les schémas varient d'un pays à l'autre. L'évolution des volumes de capital humain montre que l'évolution démographique entre hommes et femmes n'a eu finalement qu'un impact limité sur la variation du capital humain par habitant. $\mathrm{Si}$, dans tous les pays, l'amélioration du niveau d'instruction a contribué à l'augmentation du capital humain par habitant, cela n'a pas toujours été suffisant pour compenser les conséquences du vieillissement de la population, entraînant une baisse des volumes de capital humain par habitant dans certains pays. Enfin, l'analyse de sensibilité confirme que les estimations des valeurs du capital humain dépendent du choix de deux paramètres, à savoir le taux de croissance annuel du revenu réel et le taux d'actualisation. Mais la répartition du capital humain et l'évolution des volumes de capital humain dans chaque pays sont moins sensibles à ces paramètres. 
TABLE OF CONTENTS

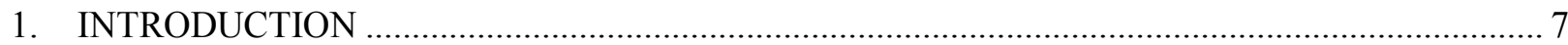

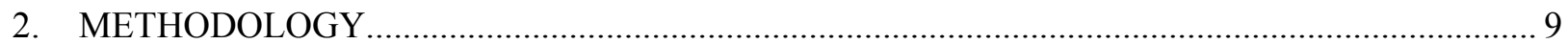

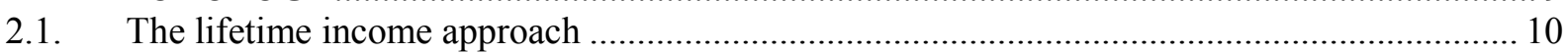

2.2. Comparisons with the SNA measures of economic capital .................................................. 11

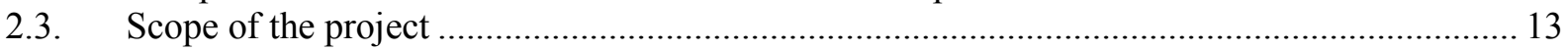

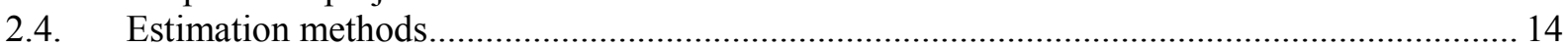

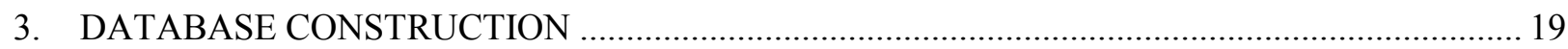

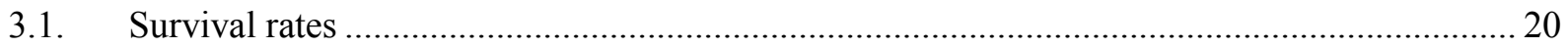

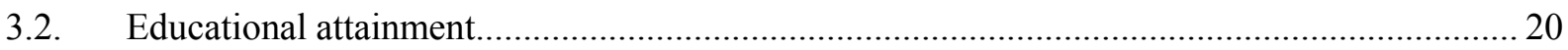

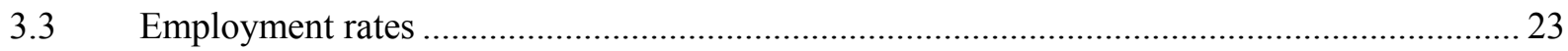

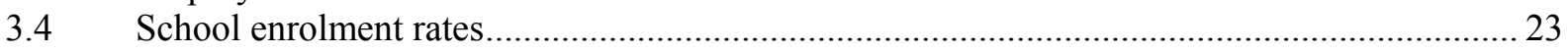

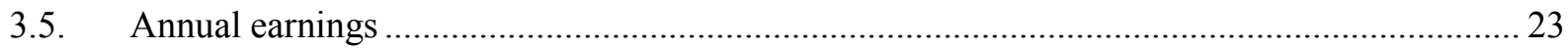

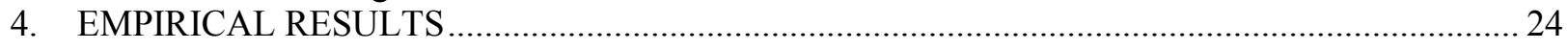

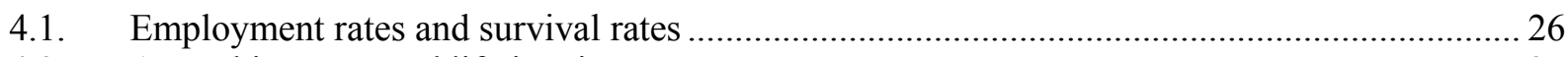

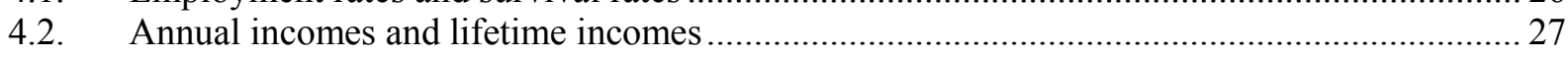

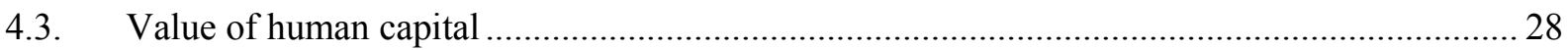

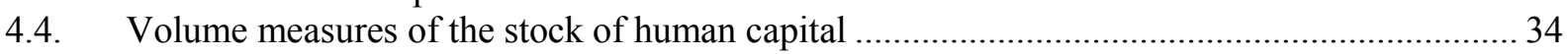

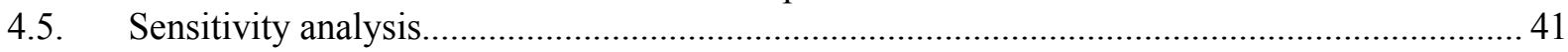

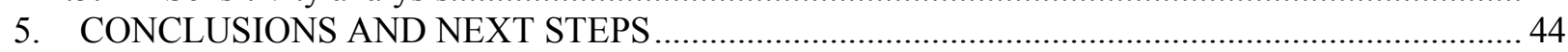

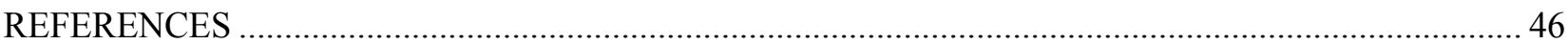

\section{Tables}

Table 1. Data availability for countries covered in the project ...................................................... 24

Table 2. Sensitivity analysis on human capital stock value and distribution for

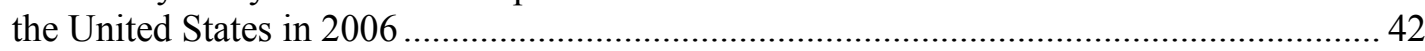

\section{Figures}

Figure 1. Annual real income growth rates used in human capital estimation.................................. 25

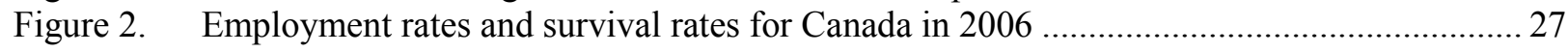

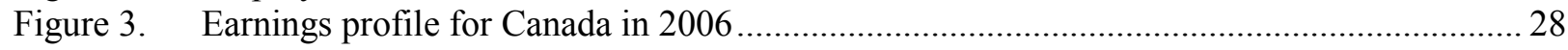

Figure 4. Stock of human capital relative to GDP and to the stock of physical capital, 2006 ........... 29

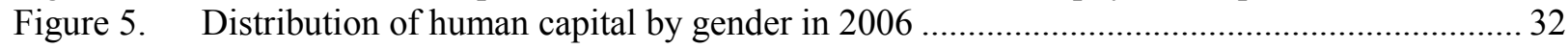

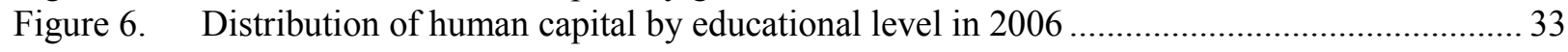

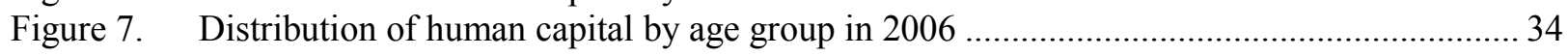

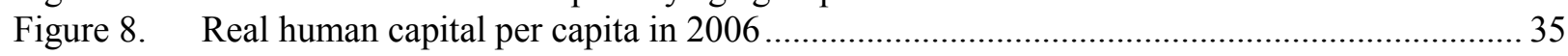

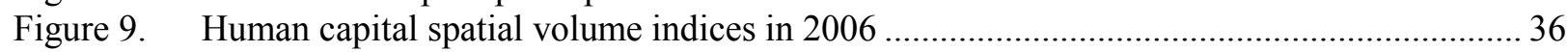

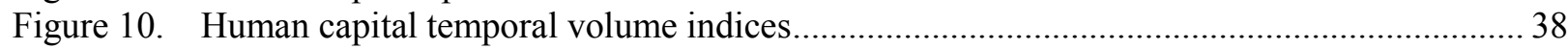

Figure 11. Decomposition of average annual growth of human capital volumes per capita due to age,

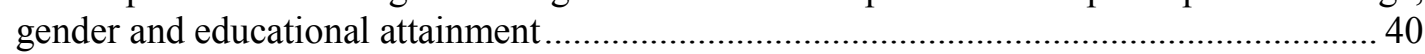

Figure 12. Sensitivity analysis on human capital temporal volume index for United States ................ 43

\section{Boxes}

Box 1. Methodological assumptions used for estimating lifetime income …..................................... 15

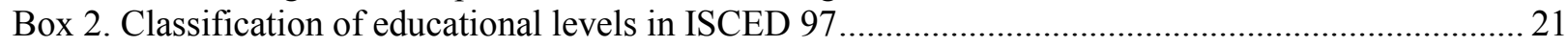




\section{INTRODUCTION}

1. Although the economics profession has long recognised that human beings and their acquired abilities are important components of the wealth of nations (Petty, 1690; Smith, 1776; Farr, 1853; Engel, 1883), it has only been with the seminal work done by Schultz (1961), Becker (1964) and Mincer (1974) that the concept of human capital has entered policy discussions and been used for addressing various research questions.

2. Several authors have underscored the critical role of human capital in driving economic growth (e.g. Romer, 1986, 1989; Lucas, 1988; Aghion and Howitt, 1998; World Bank, 2006a). Further, people's material well-being should be considered as encompassing not only their current income, but also the assets they own, including not only housing property and financial instruments but also human capital, since these assets will generate income streams over their lifetimes.

3. The concept of human capital is a broad one: the OECD defined it as "the knowledge, skills, competencies and attributes embodied in individuals that facilitate the creation of personal, social and economic well-being" (OECD, 2001).

4. This definition embraces a broad range of attributes of individuals (their formal education, but also the competencies that they have gained outside school-settings as well as people's health conditions) and a broad range of benefits stemming from it. These include not only the economic benefits that education delivers to individuals, but also non-economic benefits in the form of improved heath conditions, longer life-spans, better life styles and higher subjective well-being (Dolan et al., 2008), as well as the benefits that spill over to society at large, as in the case when education contributes to making people becoming better citizens, more tolerant and open to diversity, more willing to participate in democratic life, and better informed of environmental conditions.

5. While this broad definition is a useful reference point, all operational measures of human capital typically focus on a subset of these dimensions, or rely on different measures for its various aspects, with no ambition to bring all these aspects together into a single metric.

6. The notion of human capital is especially relevant for discussions on how to measure sustainable development. In recent debates on the subject, the UNECE/OECD/Eurostat working group on statistics for sustainable development suggested that a necessary condition for a country to grow along a sustainable development path is that its total capital stock (economic, natural, human and social capital) in per capita terms does not decline over time (UNECE, 2009).

7. This "capital approach" implies that, to monitor sustainability, we should measure changes in different types of capital. Further, when these types of capital are deemed to be substitutable with each other in the production of different well-being outcomes, measures of different types of capital should be based on a common metric, so as to allow assessing whether declines in one type of capital are offset by increases in other types.

8. Despite this wide interest in human capital, there is no agreement on how to measure its stock, even when the broad concept of human capital mentioned above is narrowed down to formal education only.

9. Some analysts have relied on physical indicators, such as average school years, shares of the population having reached various levels of educational attainment, and measures of people's 
competencies. Others have focused on expenditures in the education system, and others yet have relied on measure of the stock of human capital based on the concept of lifetime earnings. ${ }^{1}$ This diversity of approaches makes it hard to draw policy implications from comparisons of the stock of human capital across countries and calls for efforts to develop broader and more consistent methodologies.

10. The OECD has a long tradition in collecting and disseminating large sets of educational indicators ${ }^{2}$, as well as in developing methodologies for measuring the volume of education output within the System of National Accounts (Schreyer, 2010). What has been lacking until now is a framework suitable for measuring human capital in its own right, and for bringing together the wide range of factors shaping its evolution (i.e. demographic, education and labour market factors). Further, even if such an accounting framework were in place, work would need to be done to identify the corresponding data requirements and the simplified assumptions required for making this accounting framework operational.

11. To initiate efforts along these lines, the OECD together with the Fondazione Giovanni Agnelli (a leading Italian institution working on these issues) organized a workshop on human capital measurement in Turin in $2008^{3}$ that gathered some of the leading researchers and practitioners in this field from several OECD and non-OECD countries. At that workshop, a consensus was reached that measuring human capital by the lifetime income approach was the best practical option. This conclusion was supported by the several national studies that had already applied the same approach. ${ }^{4}$

12. As a follow-up to the Turin workshop, a proposal to launch an "OECD human capital project" was presented to, and endorsed by, the OECD Committee on Statistics at its meeting of June 2009. The purpose of this project was to identify common methodologies for measuring the stock of human capital for comparative analysis, both across countries and over time, and to implement these methodologies by means of existing OECD data. ${ }^{5}$

13. The OECD human capital project started in October 2009 and took the form of an international consortium consisting of 16 OECD countries (Australia, Canada, Denmark, France, Israel, Italy, Japan, Korea, Mexico, the Netherlands, New Zealand, Norway, Poland, Spain, the United Kingdom and the United States), Russia and Romania; Eurostat and the ILO also participated in the consortium. The consortium was co-ordinated by the OECD Secretariat, thanks to support provided by Statistics Norway.

14. This paper summarises the outcomes from the first phase of the project. In doing so, the paper also serves two other goals. First, it shows the feasibility of measuring human capital by applying the lifetime income approach based on data already available from the OECD statistical system. Second, it

1. All these approaches to measuring human capital have their pros and cons. For balanced discussions, see Stroombergen et al. (2002), Le et al. (2003), Fraumeni (2008) and Liu and Greaker (2009).

2. See various issues of Education at a Glance, e.g. OECD (2011).

3. More information about the Turin workshop in 2008 is available at the following website: http://www.oecd.org/document/39/0,3343,en $2649 \quad 33715 \quad 41153767 \quad 1 \quad 1 \quad 1 \quad$ 1, $00 . h t m l$

4. By the time of the Turin workshop, estimates of the value of human capital based on this methodology were available for the United States (Jorgenson and Fraumeni, 1989, 1992a, 1992b), Sweden (Ahlroth et al., 1997), Norway (Ervik et al., 2003; Greaker and Liu, 2008), the United Kingdom (O'Mahony and Stevens, 2004), Australia (Wei, 2004, 2007), New Zealand (Le et al., 2006) and Canada (Gu and Wong, 2008).

5. Monetary estimates of the stock of human capital based on the lifetime income approach used in this project could both complement and benefit from direct measures of people's skills and competencies such as those that are being developed through the OECD Programme for the International Assessment of Adult Competencies (PIAAC) (for more information on the PIAAC program, see Schleicher (2008)). 
highlights some of the policy messages that can be drawn from analysis based on these measures of human capital stock.

15. The rest of the paper is organised in the following way. Section 2 discusses the lifetime income approach used in this project, comparing these measures of human capital with those for physical capital available within the System of National Accounts; this section also describes the scope of this project and details the implementation procedures of the lifetime income approach. Section 3 describes how the OECD database was constructed. Section 4 reports a number of empirical estimates, while Section 5 concludes and identifies possible directions for future research.

\section{METHODOLOGY}

16. A monetary measure of the total stock of human capital can be derived either directly or indirectly. The indirect approach estimates human capital residually, based on the assumption that the discounted value of the benefits that the capital stock will deliver over its life will be equal, under certain assumptions, to the current monetary value of the capital asset. In the context of discussion on sustainable development, the total capital assets of each country may be thought of as generating a stream of benefits in the form of consumption goods in the future.

17. Hence, by taking the discounted value of today's consumption, and subtracting from this amount the monetary value of those capital goods for which monetary estimates of their current stocks are readily available (i.e. economic capital, market value of a range of natural assets), may provide an indirect (i.e. residual) estimate of the value of those capital stocks for which no monetary value can be observed on the market.

18. The World Bank has pioneered this approach, measuring the total stock of human capital as the difference between the total discounted value of each country's average consumption expenditures into the future (which is taken as a proxy for total wealth) and the sum of the tangible components of that wealth, i.e. produced capital and the market-component of natural capital (World Bank, 2006a, 2006b; Ruta and Hamilton, 2007). A similar approach has also been applied by Statistics Norway in the case of Norway (Greaker et al., 2005).

19. While this indirect approach can be applied to a large number of countries based on limited statistical information, it has limits. First, it obviously ignores the non-market benefits of the various capital stocks. Second, this measure is affected by measurement errors in all the terms entering the accounting identities, resulting in potential biases in the resulting estimates of human capital. Third, it cannot explain what drives the observed changes of the stock of human capital over time.

20. Direct approaches derive a measure of the stock of human capital from information on its various components. Within this family of approaches, we can further distinguish between parametric methods (which rely on econometric estimation of key parameters, see e.g. Kyriacou, 1991) and nonparametric methods (i.e. directly based on the available data). Most applications of the direct approach are of the nonparametric type; among these we can distinguish a cost-based approach, an income-based approach and an indicators-based approach.

- The cost-based approach measures human capital by looking at the stream of past investments, including investments coming from the individual, the family, employers and governments (e.g. Shultz, 1961; Kendrick, 1976; Eisner, 1985). This approach relies on information on all the costs that are incurred when producing the human capital. These costs include monetary outlays by each of the agents mentioned above, but can also be extended to account for non-market 
expenditures (e.g. imputed values of the time devoted to education by both students and their parents).

- The income-based approach measures human capital by looking at the stream of future earnings that human capital investment generates (e.g. Weisbrod, 1961; Graham and Webb, 1979; Jorgenson and Fraumeni, 1989, 1992a, 1992b). In contrast with the cost-based approach, which focuses on the input side, the income-based approach measures the stock of human capital from the output side. ${ }^{6}$

- The indicators-based approach measures human capital through various types of characteristics in the population such as literacy rates, school enrolment ratios and average years of schooling (e.g. Ederer et al, 2007, 2011; various issues of Education at a Glance). Unlike others, this approach relies on several indicators that, though rich in information, lack a common metric and, as a result, cannot be aggregated into an overall measure. This makes the indicators-based approach less suitable for comprehensive comparisons of the total stock of human capital across countries and over time, and does not allow comparing the relative importance of different types of capital, i.e. stocks of economic, natural and human capital (Stroombergen et al., 2002).

21. Although all of the approaches mentioned above have advantages and disadvantages, the (income-based) lifetime income approach was selected as the preferred methodology for the OECD human capital project. This reflected the specific perspective used in this project, which focused on developing indicators that could be used to assess the inter-temporal sustainability of a country's development path. The selection of this approach followed the discussion held at the 2009 meeting of the OECD Committee on Statistics (OECD/STD/CSTAT(2009)8) and is consistent with the conclusions drawn from literature surveys (e.g. Liu and Greaker, 2009; Fraumeni, 2008, 2009).

\subsection{The lifetime income approach}

22. The lifetime income approach, advocated by Jorgenson and Fraumeni (1989, 1992a, 1992b), measures the value of the total stock of human capital embodied in individuals as the total discounted present value of the expected future labour incomes that could be generated over the lifetime of the people currently living.

23. The choice of the lifetime income approach for measuring the total stock of human capital in the context of the OECD project reflects its advantages in bringing together, through a consistent accounting structure, a broad range of factors that shape the stock of human capital of the population living in a country: these factors include not only the total population and its structure (by age and gender) but also the expected life-span of people (a measure that reflects health conditions), their educational attainment and their labour market experiences (in terms of both their employment probabilities and the earnings they gain).

24. An additional advantage of the lifetime income approach is that changes in the stock of human capital during each accounting period can be described in terms of investment (such as formal and informal

6. While the outputs from human capital investment are of many types (i.e. monetary and non-monetary, private and public), the output measured by the lifetime income approach is limited to the private monetary benefits that accrue to the person investing in human capital. More discussions on this is provided in Section 2.3 of this paper. 
education), depreciation (such as deaths and net emigration) and revaluation (e.g. changes in the labour market premiums of education). ${ }^{7}$

25. While some of the existing applications of the lifetime income approach have provided estimates of the stock of human capital that include the lifetime income derived from both paid work (i.e. work sold on the labour market) and from non-market activities (i.e. household production and leisure time), measured through various imputations (e.g. Jorgenson and Fraumeni, 1992a), the approach used in this paper is limited to market work.

26. While the fact of providing a comprehensive monetary estimates of the stock of human capital is the main advantage of the lifetime income approach, this does not imply that the approach is immune from drawbacks. In particular:

- First, in order to calculate lifetime incomes, some judgements have to be made about discount rates and the real income growth that people currently living may expect in the future. The nature of these assumptions will obviously affect the final estimates, although their quantitative importance can be assessed through sensitivity analysis (cfr. Section 4.5).

- Second, there are many reasons to believe that labour markets do not always function in a perfect manner. In these cases, the wage rates by education used in this approach as a proxy for the monetary benefits provided by additional schooling will differ from the marginal productivity of a particular type of worker. This approach hence ignores the importance that other factors (such as workers' social background and innate abilities, or the effects of trade-unions and industry of employment) may have on shaping wage differentials. ${ }^{8}$

- Lastly, by relying on observed market wages, the monetary stock of human capital may increase when the composition of employment shifts towards higher paid workers (e.g. from women to men, from migrants to natives, from less-educated to more educated workers). Other indicators based on the lifetime income approach will however capture the effect of these compositional changes (cfr. Sections 4.3.2 and 4.4.2).

27. Despite of these conceptual drawbacks, many researchers in this field share the view that, compared to other methods, the lifetime income approach provides the most practical way to derive a monetary measure of human capital that is consistent with both economic theory and accounting standards (e.g. Abraham, 2010). Further, as described below, the lifetime income approach is also the one that is closer to the assumptions used for measuring conventional economic capital within the System of National Accounts (Fraumeni, 2009).

\subsection{Comparisons with the SNA measures of economic capital}

28. Standard investment theory underpins the measurement of both human and physical capital (see Jorgenson, 1963, 1967). ${ }^{9}$ A typical asset, no matter whether it is physical capital (such as machines,

7. One implication of the notion of human capital is that some of the expenditures that are currently classified as "consumption" within the System of National Accounts should rather be treated as "investment".

8. However, literature surveys on the returns to education (e.g. Card, 2001) suggest that the ability bias in the cross-sectional relationship between years of school and earnings may not be substantial.

9. The term "physical capital" is used here to refer to those assets that fall within the capital boundary of the System of National Accounts. 
buildings and infrastructure) or human capital (such as knowledge, skills and competencies), can be used in production over several accounting periods (i.e. for more than one year). The value of the productive service that the capital asset can generate during each accounting period is a flow concept, while the value of the asset is a stock concept.

29. Both concepts are of significance for economic analysis: the value of the capital stock is a measure of "storage of wealth", while the value of its productive services is an input into economic production. In a well-functioning market, the stock value of a capital good would be equal to the present value of the productive services that the capital good generates over its lifetime.

30. In some circumstances, only the stock value (rather than the productive service value) of a capital can be observed from the market; in this case, the challenge for capital measurement will be of deriving an estimate of the corresponding service value from the observed stock value. The measurement of traditional physical capital corresponds to this situation; as physical capital is usually sold and bought in markets, their prices (stock values) can be directly observed.

31. In other cases, however, the stock value of a capital good cannot be observed directly. This is the case of human capital, for the obvious reason that in modern societies human beings embodied with human capital are not sold and bought in the market. Nonetheless, even if the value of the stock of human capital cannot be directly observed on the market, a long stream of economic theory has argued that labour compensation can be considered as the service value that human capital provides during each accounting period. In these circumstances, the stock value of human capital can be derived by taking the present value of all the labour income streams over people's lifetime.

32. The above argument suggests that observing the stock value of one type of capital and then deriving its service value (as in the case of physical capital); or observing its service value first and then computing its stock value (as in the case of human capital) are two sides of one coin. In principle, if capital markets are efficient, both accounting methodologies should be consistent with each other.

33. In practice, the two approaches face different challenges. To derive the service value from the observed market value of a physical capital good, assumptions have to be made, for example about the ageefficiency profile of the good in question (i.e. how fast the productivity of the machine considered will fall as it ages). Similarly, to calculate the stock value of human capital from its observed service value, assumptions have to be made about the income growth that each person with a given set of characteristics may expect in the future and on the rate used to discount these future earnings. No matter how these assumptions are made, e.g. either through empirical observations or through theoretical reasoning, they are exogenous in nature. As a consequence, different assumptions will affect estimates in different ways.

34. To fully develop the accounting structure of human capital estimates, further difficulties should be overcome. For instance, human capital is acquired by learning, studying and practising. But these activities cannot be undertaken by anyone else than the person considered. As these activities do not satisfy the 'third party criterion', the acquisition of knowledge cannot be considered as a process of production according to the production boundary of the System of National Accounts, even if the services produced by educational institutions are considered as a production activity (SNA 2008, 1.54).

35. Further difficulties would have to be addressed to extend the lifetime income approach to account for non-market activities. All these considerations suggests that the construction of a human capital 
account (even one limited to formal education) should take the form of a satellite account, rather than of full integration in the standard SNA accounts. ${ }^{10}$

\subsection{Scope of the project}

36. Despite the broad definition of human capital provided above (i.e. "the knowledge, skills, competencies and attributes embodied in individuals that facilitate the creation of personal, social and economic well-being"), a number of conceptual, methodological and data limitations have restricted the scope of the project to measuring only the personal economic well-being generated through market activities. Such economic well-being is measured by the lifetime labour income that results from human capital investment and that accrues to individual persons themselves. This does not imply neglecting the wider range of benefits from human capital investment that accrue to the society at large, nor other noneconomic benefits that accrue to individuals, but simply recognises that current valuation methodologies do not allow accounting for these other effects.

37. Beyond the conceptual limitations of the lifetime income approach mentioned in Section 2.2, some of the practical limitations of the approach implemented here include the following:

- First, while ideally the scope of human capital measurement should cover the whole population, data availability limits the possibility of implementing such a comprehensive approach. Thus, the measures presented here are limited to the population of working age (15 to 64). ${ }^{11}$. This implies neglecting both the human capital embodied in children below age 15 and the possibility that elderly people will extend the "service life" of their own skills by staying longer in the labour market. The progressive increase (beyond the age of 65) of elderly people's participation rates, partly due to pension reforms, implies that the monetary estimates of the stock of human capital presented here will be biased downwards.

- Second, the human capital measures presented in this paper relate to the human resources in use (or realized) in a given country and year, rather than to the human resources that are available. For example, individuals' decisions to withdraw from the labour market, as well as institutional characteristics that affect earnings gaps between men and women, will affect the measures of realised human capital shown here.

- Third, the estimates of human capital shown in this paper, based on the earnings of workers classified by the highest level of education achieved, may confound the effects of different factors impacting on earnings. ${ }^{12}$ For example, higher earnings due to better health conditions are indirectly included in the estimates shown in this paper, whether or not these better health conditions are attributable to investment in education.

10. A first difficulty to extend the lifetime income approach to non-market activities is how to impute the value of the time devoted to learning (including both the students' own time as well as parents' and volunteer's time used for helping students). A second difficulty is the availability of detailed information on how individuals use their time.

11. On the other hand, one may argue that if the research focus is on a country's current economic activities, the working age population (15-64), rather than the total population, might be more relevant, thus deserving a separate treatment.

12. Although formal education is the most important type of human capital investment, other factors (such as early parenting, on-the-job training, etc.) will affect individuals' earnings (Rosen, 1989; Abraham, 2010). However, distinguishing the effect from various factors would require econometric estimates drawn form earnings equations at the individual level. 
- Finally, as already mentioned, the estimates of human capital shown here are limited to market activities. In other terms, the potential effects of education in raising people's productivity in terms of household production (e.g. helping with children's study, making healthier food for family) are ignored.

\subsection{Estimation methods}

\subsubsection{Value of human capital}

38. Implementing the lifetime income approach requires three major steps.

- First, a database containing the economic value of labour market activities for various categories of people needs to be compiled. This database should include, at minimum, information on the number of people, their earnings (when employed), as well as their school enrolment rates, employment rates, and survival rates. All these data should, ideally, be cross-classified by gender, age and the highest level of educational attainment achieved. ${ }^{13}$

- Second, an algorithm needs to be constructed for calculating the lifetime income for a representative individual in each category in the database. The fundamental assumption applied here is that an individual of a given age, gender and educational level will have in year $t+1$ the same labour income (adjusted by the real income growth rate expected in the future and by the survival rate of each person) and other characteristics (e.g. school enrolment rate, employment rate and survival rate, etc.) of a person who, in year $t$, is one year older but has otherwise the same characteristics (e.g. gender and educational level). This assumption, which is unlikely to hold in practice, ${ }^{14}$ simply reflects the nature of data used in this project, i.e. cross-sectional data for different cohorts rather than longitudinal data following the same people over time. ${ }^{15}$ Box 1 provides a more complete specification of the methodological assumptions used to estimate lifetime labour income.

- Third, the measures of lifetime labour income per capita estimated through equations (1) and (2) shown in Box 1 need to be applied to all individuals in each age/educational category to compute the human capital stock for that category. Summing up the stocks of human capital across all categories yields an estimate of the aggregate value of the human capital stock $(\mathrm{HCV})$ for each country. ${ }^{16}$

13. In practice, most data on survival rates do not distinguish between different categories of educational attainment (i.e. survival rates differ only according to the age and gender of each person).

14. In other terms, the methodology used here ignores "cohort effects", e.g. the possibility that a person born in the $21^{\text {st }}$ century may expect a different income flows in the future than a person born in the 1990s.

15. A natural modification of this approach would be to use not only cross-sectional but also time-series information in order to estimate the future earnings of various groups of people. For example, to smooth the short-term business cycle effects that cannot be removed by applying the original Jorgenson-Fraumeni approach (which relies on current cross-sectional information only), Wei (2008) relies on a cohort-based estimation method of future earnings.

16. In formal terms, the total stock of human capital is computed as:

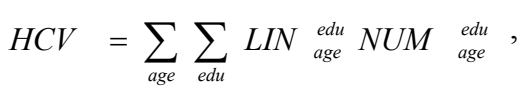




\section{Box 1. Methodological assumptions used for estimating lifetime income}

This project distinguishes between three stages in the life cycle of an individual of working age (i.e. between 15 and 64 years of age): i) 'study-and-work' (15-40); ; ii) 'work-only' (41-64); and iii) 'retirement only' (65 and above). Based on this assumption, the lifetime labour income of an individual can be computed as follows:

- $\quad$ For persons aged 65 and over (i.e. 'retirement only' stage), their lifetime labour income is zero since, by assumption, these persons will not receive earnings after withdrawing from the labour market.

- For persons aged 41 to 64 (i.e. 'work-only' stage), their lifetime labour income is estimated as follows:

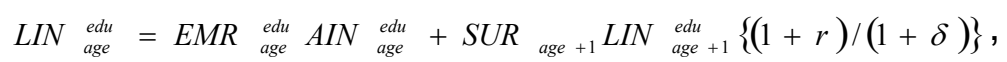

where $L I N_{a g e}^{e d u}$ is the present value of lifetime labour income for a representative individual with educational level of "edu" at the age of "age"; $E M R_{a g e}^{e d u}$ is the employment rate for this individual; $A I N_{a g e}^{e d u}$ is his/her current annual labour income, if employed; $S U R_{\text {age }}$ is the probability of surviving one more year given that this individual is at the age of "age"; $r$ is the annual growth rate of the labour income (in real terms) of a person of these characteristics in the future; $\delta$ is the annual discount rate. The lifetime income of a representative individual during the 'work-only' stage is therefore estimated as the sum of two parts: the first part is the current labour income, adjusted by employment rate (the first term in equation (1)); the second part is the lifetime income in the next year, adjusted by the corresponding survival rate, income growth rate and discount rate (the second term in equation (1)).

- $\quad$ For persons aged 15 to 40 (i.e. 'study-and-work' stage), their lifetime labour income is estimated as follows:

$$
\begin{aligned}
& L I N_{a g e}^{e d u}=E M R_{a g e}^{e d u} A I N N_{a g e}^{e d u}+\left\{1-\sum_{e d u} E N R_{a g e}^{e d u-\overline{e d u}}\right\} S U R_{a g e+1}^{e} L I N_{a g e+1}^{e d u}\{(1+r) /(1+\delta)\} \\
& +\sum_{\overline{e d u}} E N R_{a g e}^{e d u-\overline{e d u}}\left\{\left(\sum_{t=1}^{t_{\text {edu }}-\overline{e d u}} S U R_{a g e+t} L I N_{a g e+t}^{\overline{e d u}}\{(1+r) /(1+\delta)\}^{t}\right) / t_{e d u-\overline{e d u}}\right\},
\end{aligned}
$$

where $E N R \underbrace{\text { edu }-\overline{e d u}}_{a g e}$ is the school enrolment rate for a representative individual with educational level of "edu" pursuing studies into a higher educational level of " $\overline{e d u}$ "; $t_{e d u-\overline{e d u}}$ is the school duration for this individual with educational level of "edu" to complete a higher educational level of " $\overline{e d u}$ ".

During the 'study-and-work' stage, a representative individual in the next year will be confronted to two courses of action: the first is to continue his/her school and (after completing study and having gained a higher educational level) to receive income as $\left\{\left(\sum_{t=1}^{t_{\text {edu }}-\overline{e d u}} S U R_{a g e+t} L I N_{\text {age }+t}^{\overline{e d u}}\{(1+r) /(1+\delta)\}^{t}\right) / t_{\text {edu }-\overline{e d u}}\right\}$, with the probability

where $N U M_{a g e}^{e d u}$ is the number of persons in the corresponding age/educational category. It should be noted that equations (1), (2) and (3) are applied separately to both men and women; this allows computing the stock of human capital by gender.

17. The cut-off at age 40 for the lower bound of the "study-and-work" stage is due to the fact that information on the number of students enrolled in different educational levels from the OECD database is available until age 40. Many countries have witnessed in recent years a quite significant increase in the number of adults (more than 40 years old) attending schools for further education (http://dotstat.oecd.org/wbos/Index.aspx). 
of $\sum_{\overline{e d u}} E N R \substack{\text { age } \\ \text { age }}_{\overline{e d u}}$; the second is to start working (holding the same educational level as before) and earn income

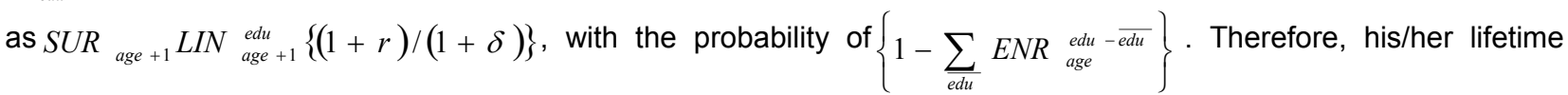
income in the next year is the expected value of the outcomes of these two courses of action (i.e. the sum of the second and the third terms in equation (2)).

The empirical implementation of equations (1) and (2) is based on backwards recursion. With this approach, the lifetime labour income of a person aged 64 (i.e. one year before retirement) is simply his/her current labour income (the first term in equations (1) and (2)) because his/her lifetime labour income at 65 is zero by construction. Similarly, the lifetime labour income of a person aged 63 is equal to his current labour income plus the present value of the lifetime labour income of a person aged 64, and so forth.

In estimating lifetime labour income by using equations (1) and (2), several practical assumptions are made, some of which are used as well by other studies in the field (e.g. Gu and Wong, 2008; Le et al., 2006; Liu and Greaker, 2009; Wei, 2004, 2007). The most important of these assumptions are:

- Individuals can only enrol in a higher educational level than the one they have already completed.

- No further enrolment is allowed for people having already achieved the highest educational level.

- Students enrolled in educational institutions requiring more than one year to complete are assumed to be evenly distributed across the total study-period (school duration). This is equivalent to saying that, during each school-year, the same proportion of all students will complete the study.

- $\quad$ No delaying, quitting or skipping is allowed during the whole study period.

\subsubsection{Volume of human capital}

39. Estimates of human capital values based on the methodology outlined above are in current prices. To monitor the evolution of human capital within a country, values in current prices are not enough, as changes of human capital values may be driven by changes in both human capital volumes and in price between two periods in time. Similarly, the difference of human capital value at one point in time between two countries may reflect both differences of human capital volumes and differences of the price levels in the two countries.

40. To compare human capital either across countries or over time, as required in analyses of economic growth, productivity and inflation, we need to derive estimates of human capital volumes from the estimated human capital values, i.e. to decompose changes of human capital at current prices into changes of price levels between two periods (or two countries) and changes of human capital volumes. Since there are two dimensions for comparisons (across countries and over time), we have constructed two types of human capital indices, i.e. spatial volume and temporal volume indices.

41. Given the three terms of value, volume and price, in principle any one can be derived from the other two. In practice, there are two approaches to deriving volume indexes. The first, which is more frequently applied, derives volume estimates by dividing value by a price deflator. The second directly constructs volume estimates and then derives price by dividing the value by such constructed volume index. This paper applies the first approach for constructing human capital spatial volume index, and the second one for constructing human capital temporal volume index. 


\subsubsection{Spatial volume index}

42. The purpose of constructing spatial human capital volume index is to compare human capital in real terms between different countries at one point in time, since price levels for the same set of goods and services in different countries can differ. The approach used here is to simply divide estimated human capital values by the purchasing power parities (PPPs) for each country.

43. The OECD statistical system provides three types of estimates for purchasing power parities: i) PPPs for GDP; ii) PPPs for private consumption; and iii) PPPs for actual individual consumption (which includes prices for the in-kind individual services provided by governments to households). Since incomes generated through human capital investment will flow to final consumption, the PPPs used in this project are those for private consumption.

44. Depending on the purpose of the exercise, other PPPs could be applied. For instance, when evaluating human capital from individuals' perspective, the lifetime income they can earn should include not only wages and salaries after taxes, but also other payments and transfers (either in cash or in kind) flowing to them from other sources (e.g. employer's contribution to social security, government transfer); in this case, the relevant deflator may be the PPPs for actual individual consumption.

45. The income concept applied in this project is that of "wages and salaries" as defined in the System of National Accounts; this includes workers own contributions to social security, but not those paid by employers. In part due to this, the PPPs for private consumption are used for constructing the spatial volume index.

46. Ideally, the construction of spatial volume index needs to use as deflators the specific PPPs for human capital rather than the PPPs for private consumption used in this paper. Due to data constraint, the choice of the latter is just an approximation, which will lead to some biases when making country comparisons. However, it is challenging to make any judgements at this stage on whether the resulting biases are upwards or downwards for each project participating country. Thus, we leave this issue to be further investigated in the future.

\subsubsection{Temporal volume index}

47. To compare stocks of human capital in real terms over time, a temporal volume index needs to be constructed. This project relies on the Tornqvist index method ${ }^{18}$, whose methodology is outlined in Jorgenson et al. (2005) and has been applied in several national studies on human capital measurement (e.g. Gu and Wong, 2010; Li et al., 2010).

48. According to this methodology, the growth rate of the temporal volume index of human capital is calculated as the weighted sum of the growth rates of the number of individuals in different categories of the population (such as age, gender and educational attainment), using their shares of the nominal value of human capital as corresponding weights. In other terms:

$$
\Delta \ln H C I=\sum_{\text {age edu }} \sum_{\text {gender }} \overline{V S H}_{\text {age,gender }}^{\text {edu }} \Delta \ln N U M_{\text {age,gender }}^{\text {edu }},
$$

where $H C I$ stands for the temporal human capital volume index, and $\Delta$ is the first difference operation between two periods of time, $t$ and $t-1$.

18. The Tornqvist index is a discrete approximation to a continuous Divisia index and has been shown to be an exact superlative index number (Diewert, 1976). 
49. Further, weights in equation (4) are given by the share of each category of population in the total value of human capital averaged across the two periods, i.e.:

$$
\overline{V S H}_{\text {age,gender }}^{\text {edu }}=\frac{1}{2}\left\{V S H_{\text {age,gender }}^{\text {edu }}(t)+V S H_{\text {age,gender }}^{\text {edu }}(t-1)\right\}, \text { and }
$$

$$
V S H_{\text {age,gender }}^{\text {edu }}=\frac{L I N_{a g e, \text { gender }}^{\text {edu }} N U M_{\text {age,gender }}^{\text {edu }}}{\sum_{\text {age edu }} \sum_{\text {gender }} \sum_{\text {age, gender }} N U M_{\text {age, gender }}^{\text {edu }}},
$$

where $L I N_{\text {age,gender }}^{\text {edu }}$ refers to the lifetime income of a representative individual classified by age, gender and educational level and is calculated by using equations (1) and/or (2).

50. In principal, the more detailed the categories of population, the more accurate the volume index will be. At one extreme end, one could argue that each person should be treated differently from anyone else and thus be classified as a unique category; in practice, the data requirements to implement this approach are daunting, so that the approach is not practically feasible.

51. Despite this consideration, as long as data allows, the population should be classified with as much detailed as possible. In this project, the working age population has been classified by three characteristics: age, gender and educational level. With richer data, the classification might be extended to include more characteristics such as occupation, industry of employment etc. as all these characteristics have important bearings in determining individuals' wages.

52. Equation (4) shows that the temporal volume index will increase if the composition of population shifts towards those categories of peoples having higher lifetime incomes. This may occur, for example, when more people attend higher education (which is generally associated with higher lifetime income) or when the composition of the working age population shifts towards younger people (because younger people have more remaining working years and so higher lifetime income, even if they usually have lower annual income at the time they enter into the labour market).

53. For some purposes, such as implementing sustainability assessment, more interest will be put on monitoring changes of human capital per capita. According to the notion of 'weak sustainability', a necessary condition for a country to follow a sustainable path is that its total capital stock per capita does not decrease over time (UNECE, 2009). The growth rate of human capital per capita is just the difference between the growth rate of the human capital volume $(H C I)$ and that of population $(N U M)$.

54. To account for the contribution of different characteristics (e.g. age, gender and educational level) to the real growth of human capital per capita, first-order partial Tornqvist indices for each characteristic were derived. For instance, a first-order partial index for gender is defined as:

$$
\begin{aligned}
& \Delta \ln H C I_{\text {gender }}=\sum_{\text {gender }} \overline{V S H}_{\text {gender }} \Delta \ln \left(\sum_{\text {age }} \sum_{\text {edu }} N U M_{\text {age,gender }}^{\text {edu }}\right), \text { where } \\
& \overline{V S H}_{\text {gender }}=\frac{1}{2}\left\{V S H_{\text {gender }}(t)+V S H_{\text {gender }}(t-1)\right\}, \text { and } \\
& V S H_{\text {gender }}=\sum_{\text {age edu }} \sum_{\text {ed }} V S H_{\text {age,gender }}^{\text {edu }} .
\end{aligned}
$$


55. The first-order partial volume index for gender as shown in equation (7) captures the shift of the population structure between men and women, while ignoring other shifts among age groups and educational categories within each gender. Similarly, the first-order partial volume indices for age (or educational attainment categories) measure the shift between age groups only (or between educational categories only).

56. In this approach, the contribution of each characteristic to the real growth of human capital per capita is defined as the difference between the growth of the first-order partial indices of human capital for each characteristic (age, gender, and educational level) and the growth of the number of individuals in the population.

57. It should be noted that the sum of these contributions across characteristics will differ from the overall growth of human capital per capita, as the sum of the contribution of the different characteristics represents only the first-order approximation to the growth of human capital per capita. ${ }^{19}$

\section{DATABASE CONSTRUCTION}

58. Although the lifetime income approach requires information by single year of age, all data available within the OECD statistics system, as well as most data available to researchers in individual countries, refer to either 5-year or 10-year age groups.

59. To develop a database suitable for this exercise, the OECD Secretariat has relied on a number of practical assumptions and imputation methods to generate data by single year of age. For example, data on the number of students by single year of age were estimated based on information on the average enrolment rate of a given age group, and on the number of people of each age. These assumptions and imputations obviously affect the quality of the estimates presented in this paper.

60. A further factor shaping the estimates of the stock of human capital presented here is the quality of the underlying data in the various years. In general, the quality of the OECD Education database, the principal data source for this project, is lower for the years preceding the mid-1990s. In particular:

- School enrolment data for most countries are of better quality starting from 1998, partly reflecting changes in the International Standard Classification of Education (from ISCED 67 to ISCED 97) implemented around that year.

- Data on annual earnings by educational attainment categories are only available since 1997 for most countries participating in the project.

- Similarly, the OECD Education database contains two educational attainment datasets: the first, with more detailed categories, starts for most countries from the 1990s; and the second, with more aggregated categories, provides time-series going back longer in time.

61. Because of these factors, it was decided that, in the first stage of the project, estimates of the stock of human capital would start from 1997 for most countries.

19. Higher order partial volume indices and their corresponding contributions to the growth of human capital per capita have not been calculated in this study. For an example of such applications, see Jorgenson et al. (2005) and Fraumeni (2011). 
62. For each country participating in the consortium, a database was established consisting of the five data sets described below covering the various elements that enter the estimation of the stock of human capital based on the chosen methodology.

\subsection{Survival rates}

63. The survival rate is the conditional probability that a person who is alive in year $t$ will also be living in year $t+1$. Information on survival rates, by gender and individual year of age, was mainly derived from country life-tables published in the Human Mortality Database (http://www.mortality.org). For a few countries that are not included in this database, data on survival rates were obtained through bilateral contacts with country correspondents.

64. Several studies show that people with higher educational attainment also have longer lifeexpectancy and higher survival rates. This may reflect a range of factors, such as having a healthier lifestyle (e.g. doing more exercise, having a healthier diet), having better working and living conditions, and having greater access to quality health-care (e.g. OECD, 2010a). Despite this evidence, it is difficult to find comparative data on the extent to which higher educational attainment improves survival rates in each country. For this reason, this project relies on the same survival rate for all people of a given age and gender. The use of differential survival rates by educational levels could be addressed in future research.

\subsection{Educational attainment}

65. Educational attainment in each country participating in the project was based on the categories defined in ISCED 97 (Box 2). It should be mentioned, however, that no country adheres exactly to this classification, and almost every country relied on detailed codes that differed, to some extent, from those used by others: some codes were missing in many countries, and some countries combined two or more codes together. Furthermore, a few countries have detailed codes that are not specified in Box 2. In these cases, judgements have been used to translate the national classifications into the codes shown in Box 2 . 


\section{Box 2. Classification of educational levels in ISCED 97}

The International Standard Classification of Education (ISCED) developed by UNESCO is based on standard concepts, definitions and classifications, and aims to provide a tool suitable for assembling, compiling and presenting comparable statistics on education both within countries and internationally. ISCED 97 covers primarily two crossclassification variables: i) the level of education; and ii) the field of education. Due to data constraint, the OECD human capital project only relied on the classification of educational levels, based on the following main categories:

- $\quad$ Level 0, Pre-primary education;

- $\quad$ Level 1, Primary education or first stage of basic education;

- $\quad$ Level 2, Lower secondary or second stage of basic education;

- $\quad$ Level 3, Upper secondary education;

- Level 4, Post-secondary non-tertiary education;

- Level 5, First stage of tertiary education; and

- Level 6 , Second stage of tertiary education.

Except for Level 0 and 1, the above-defined categories can be further sub-classified according to the destination for which the programs have been designated, resulting in more detailed classifications. This information is used to determine the detailed transition patterns from lower to higher educational levels shown in the figure below. In particular, it should be noted that:

- $\quad$ Level 2 encompasses sub-levels 2A (designed to provide direct access to Level 3 in a sequence which would ultimately lead to tertiary education, i.e. entrance to $3 \mathrm{~A}$ or $3 \mathrm{~B}$ ); $2 \mathrm{~B}$ (designed to provide direct access to $3 \mathrm{C}$ ); and $2 \mathrm{C}$ (primarily designed to lead to direct access to labour market at the end of this level).

- Level 3 consists of sub-levels 3A (designed to provide direct access to 5A); 3B (designed to provide direct access to $5 \mathrm{~B}$ ); and $3 \mathrm{C}$ (designed to lead directly to labour market or to Level 4 or other Level 3 programs).

- Level 4 consists of sub-levels 4A (prepared for entry to Level 5); and 4B (primarily designed for direct labour market entry).

- Level 5 includes sub-levels 5A (theoretically based research and preparatory courses of history, philosophy, mathematics, etc., or giving access to professions with high skills requirements such as medicine, dentistry, architecture, etc.); and 5B (programs that are practical/technical/occupationally specific). 


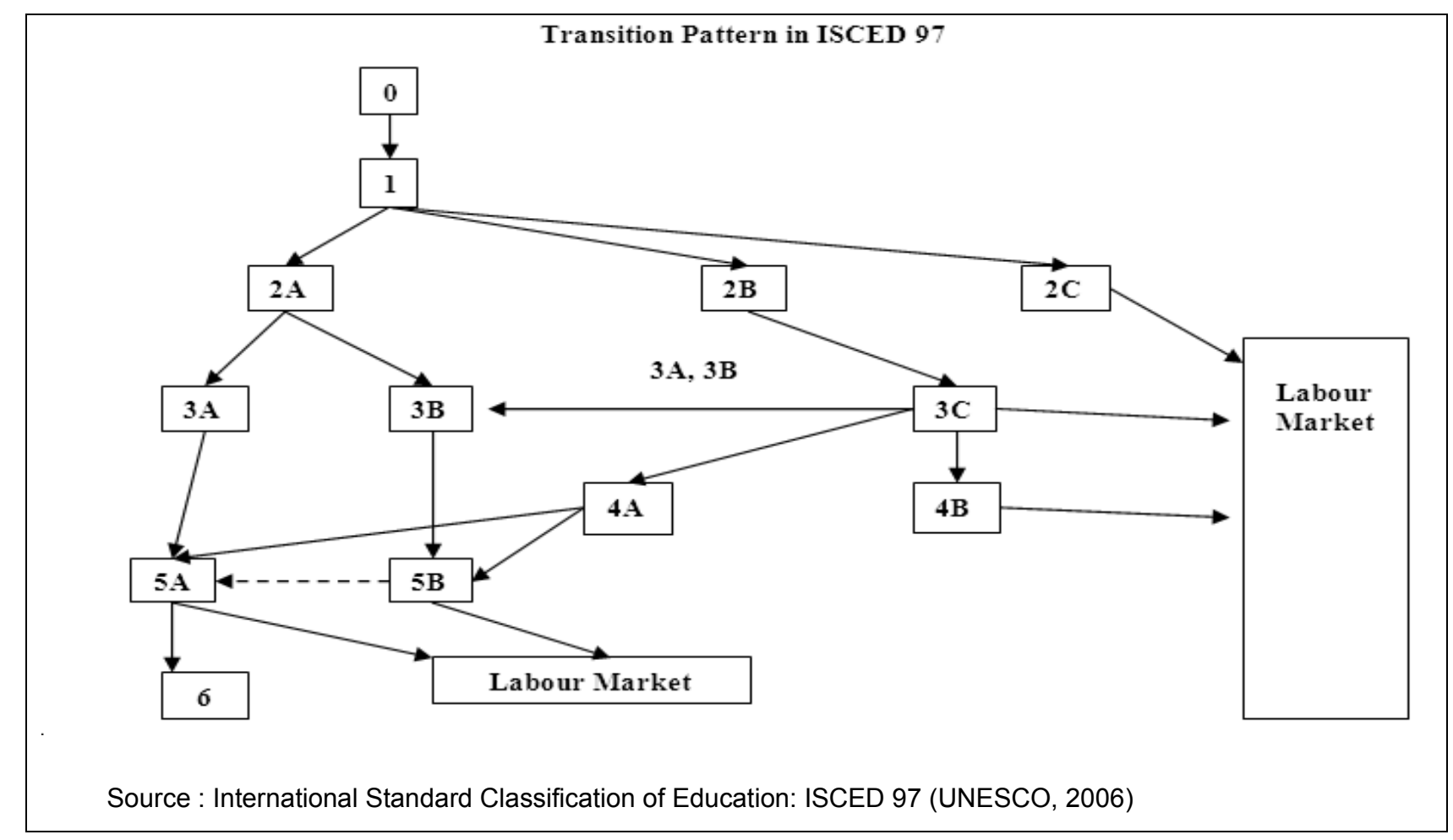

66. When considering the transitions between educational levels, further information is needed both on the transition patterns from lower to higher education and on school-duration within each educational level. Country information on school-duration for each educational level is collected by the UNESCO's Institute for Statistics, the OECD and Eurostat over 60 countries worldwide. ${ }^{20}$ This database provides information on school duration from 2000 to 2007, although data are not always available for all years.

67. For missing years as well as for years before 2000, estimates were based on the assumption that school duration in each country was the same as that in the closest available year in the period of $2000-$ 2007.

68. Information on the number of people by the highest educational attainment completed is available in the OECD Education database. These data are mostly based on national Labour Force Surveys. For most countries, these data are available by gender, educational level and 5-year age groups for people between age 15 and 64 .

69. Two adjustments to the data on number of people by educational attainment were applied. First, data on the working age population by educational attainment were benchmarked to the levels (by gender and 5-year age groups) available within the OECD Demographic Database. This adjustment (which was small in most cases) was performed in order to assure the coherence between the educational and demographic information used in the project. Second, in order to obtain data by individual year of age from the available data referring to 5-year age groups, national data on the population by gender and individual year of age were used to interpolate across different educational categories.

20. For methodological issues please refer to 2004 Data Collection on Education Systems - UOE data collection manual (OECD, 2004). 


\subsection{Employment rates}

70. OECD data on employment rates by gender and educational level are based on the same source (national Labour Force Surveys) that was used for educational attainment data. Employment rates were calculated as the ratio of the number of employed persons to that of total population in each group classified by gender, age and educational attainment. ${ }^{21}$

71. Data on employment rates by 5-year age group were broken down into data by individual years of age based on the assumption that the employment rate for each group applied equally to each single year within the corresponding age group.

\subsection{School enrolment rates}

72. Information on the number of students by gender and age (by single year of age up to 29, by 5year of age for the groups 30-34 and 35-39, and by one group for all people aged 40 and above) enrolled in different educational levels, classified according to ISCED 97 categories, is available in the OECD online databank (http://dotstat.oecd.org/wbos/Index.aspx).

73. Data on the number of students in each educational category, combined with data on the number of people by their highest educational attainment, allow computing school enrolment rates as needed for the purposes of this project; these are defined as the share of people who, having completed a given level of education, then enrolled in the level above. For simplicity, these school enrolment rates were computed only up to age 40. For people aged 30 and above, the assumption made to obtain data by individual year of age is that the enrolment rate for each single year within the age groups 30-34, and 35-39 is the same as that for the corresponding age group.

\subsection{Annual earnings}

74. Data on annual earnings by gender, age groups and educational attainment are available through the OECD Education database. The original sources of these data vary across countries (labour force surveys, household income surveys and other sources). Partially for this reason, the earnings concept used and the reference period for the earnings paid (i.e. annual, monthly and weekly) may differ across countries. For example, while some countries provide estimates of annual earnings (based on the weekly and monthly data included in the original sources), other countries only provide monthly or weekly earnings data, as available in national sources.

75. The earnings data in the OECD Education database may also reflect differences in how part-time and full time workers (as well as students holding a paid job) were treated by the national correspondents providing these earnings estimates to the OECD. A more detailed assessment of these country differences in earnings' definitions (e.g. whether they include employers' social security contributions) will be pursued in later stages of this project.

76. Because of differences in the exact definition of earnings used in the OECD Education database, earnings data by educational attainment were benchmarked on the series "wages and salaries" per employee as available from the OECD Annual National Accounts. This implies that ratios between the

21. In the case of missing values for some population groups, it was assumed that the corresponding employment rate were equal to $100 \%$. Since missing data on employment rates occurred for very few groups, the upward bias due to this assumption on the estimated results is unlikely to be significant. 
earnings for different educational categories (from the OECD Education database) were applied to the national account series of "wages and salaries" per employee. This procedure allowed deriving estimates of the value of annual earnings by gender, age and educational levels that are consistent with SNA totals. ${ }^{22}$

77. Two additional adjustments were applied to the "benchmarked" earnings data described above. First, in order to obtain earnings by single year of age, a parabolic curve was fitted through the observations of annual earnings by age groups (15-24, 25-29, 30-34, 35-44, 45-54, 55-64). Second, as the educational categories in the OECD annual earnings datasets do not always match those in the educational attainments datasets, imputations were used to generate annual earnings consistent with the educational levels shown in the educational attainment datasets.

\section{EMPIRICAL RESULTS}

78. This section describes quantitative estimates from the project as they pertain to overall values of the stock of human capital, their distribution between people with various characteristics, and volume comparisons both across countries and over time. Due to data limitation, monetary estimates of the stock of human capital have been computed only for fourteen OECD countries (Australia, Canada, Denmark, France, Israel, Italy, Korea, the Netherlands, New Zealand, Norway, Poland, Spain, the United Kingdom and the United States), and one non-member country (Romania). These estimates refer to the years for which data are available, as detailed in Table 1.

79. The available years for most of the countries participating in the project are typically from around 1997 to around 2007, with a few countries missing specific years over this period. Other countries only have data covering a shorter time span. For country comparisons, the year 2006 has been chosen as benchmark since this is the year where country-coverage is the most comprehensive.

Table 1. Data availability for countries covered in the project

\begin{tabular}{ll}
\hline Country & Data availability \\
\hline Australia & $1997,1999,2001$ \\
Canada & $1997-1999,2003-2006$ \\
Denmark & $1998-1999,2001-2002$ \\
France & $1998-1999,2002-2007$ \\
Israel & $2002-2007$ \\
Italy & $1998,2000,2002,2004,2006$ \\
Japan & No data \\
Korea & $1998-2007$ \\
Mexico & No data \\
Netherlands & 2002,2006 \\
New Zealand & $1997-2007$ \\
Norway & $1997-1999,2001-2006$ \\
Poland & $1999,2001-2002,2004,2006$ \\
Romania & 2002,2006 \\
Russian Federation & No data \\
Spain & $2001-2002,2004,2006$ \\
United Kingdom & $1997-2001,2003-2007$ \\
United States & $1997-2000,2002-2007$ \\
\hline
\end{tabular}

Note: The statistical data for Israel are supplied by and under the responsibility of the relevant Israeli authorities. The use of such data by the OECD is without prejudice to the status of the Golan Heights, East Jerusalem and Israeli settlements in the West Bank under the terms of international law.

Source: OECD Human capital project.

22. A similar adjustment method has been applied to align the earnings data from INES Network collection to those of National Accounts (see "A proposal for indicators linking education to economic growth", OECD document, INES-LSO-WG-ECO (2011)1). 
80. Measuring the stock of human capital in each country based on the retained approach requires making (arbitrary) assumptions on future earnings growth and discount rates. In this paper, the annual discount rate was set at $4.58 \%$ for all countries (the same value used by Jorgenson and Fraumeni for the United States in their 1992 study).

81. Conversely, country-specific assumptions on real earnings growth in the future were based on the OECD Medium-term Baseline. This baseline is prepared by the OECD Economics Directorate based on historical data and short-tem projections, and extended to the medium term based on assumptions about the growth of potential output in each country. This medium-term baseline is used by the OECD for much of its policy-analysis (OECD, 2009). ${ }^{23}$

Figure 1. Annual real income growth rates used in human capital estimation

Percentages

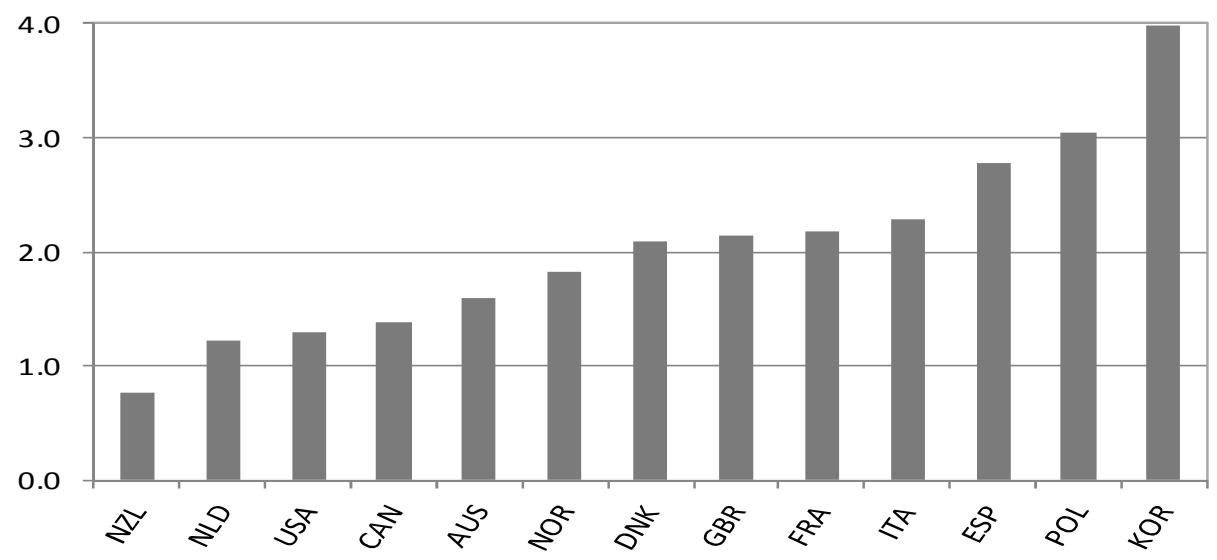

Source: OECD Medium term baseline.

82. Using data from this Medium-term scenario, the annual real income growth rate was computed as the geometric mean of real wages and salaries per employee for the total economy (including government workers) over the period 1960-2017 (Figure 1). ${ }^{24}$ Due to lack of information on Israel and Romania in the OECD Medium-term Baseline, this parameter for these two countries was set at the level of $1.32 \%$ (the rate used by Jorgenson and Fraumeni for the United States in their 1992 study).

23. Earlier estimates from this project relied on common assumptions for all participating countries, i.e. a real income growth of $1.32 \%$ per year and a discount rate of $4.58 \%$. These two values were those used by Jorgenson and Yun (1990) and Jorgenson and Fraumeni (1992a) in their estimations for the United States, and corresponded to their estimates of the annual growth rate of (Harrod neutral) productivity and of the long-run rate of return for the private sector of the economy. The choice of common assumptions for these two parameters was mainly based on the need of simplicity. Based on such simplified assumptions, preliminary estimates were presented in a "Project Progress Report" and in a paper presented at the CSTAT meeting of June 2010 (OECD/STD/CSTAT/RD(2010)3) and at the $31^{\text {st }}$ IARIW conference (OECD, 2010b), respectively.

24. The two decimals in the values of $1.32 \%$ and $4.58 \%$ are used here just to show the consistency with the values used by Jorgenson and Fraumeni (1992a); they are not meant to suggest a high degree of precision in the estimates shown in this paper. 


\subsection{Employment rates and survival rates}

83. A first set of estimates from the project relates to observations of country-specific employment rates and survival rates. These are shown here as they critically influence the human capital estimates reported later. Figure 2, which shows results for Canada in 2006, highlights patterns that hold for all countries covered in the project and that are in line with those reported in several national studies (e.g. Liu and Greaker, 2009; Gu and Wong, 2010). In particular:

- The higher the educational level, the higher the employment rate of each group; this pattern holds for both men and women, and for most age groups.

- The difference of employment rate between adjacent educational levels becomes smaller as the educational level increases.

- The employment rate is lowest at the two ends of working life. For women, and especially for those with lower education, a typical "M" shape pattern can be observed, with the lower employment rates at the bottoms attained around age 25 to 39, i.e. the age range where most women become mothers.

- Regardless of their educational levels, employment rates are higher for men than for women, except at some young ages. These gender differences are largest for people with less than upper secondary education (Level $0 / 1$ and Level 2), and for younger cohorts (left lower panel in Figure 2).

- Survival rates decline with age, especially in older ages, for both men and women. At all age, women have higher survival rate than men (right lower panel in Figure 2). 
Figure 2. Employment rates and survival rates for Canada in 2006

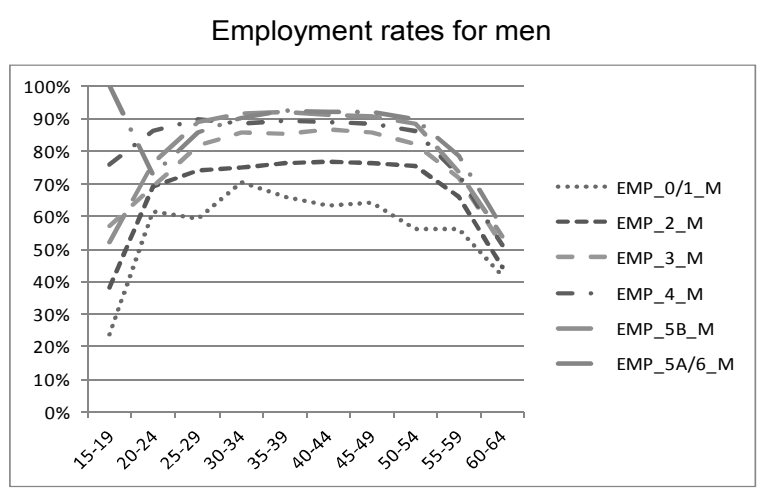

Gaps in employment rates between men and women

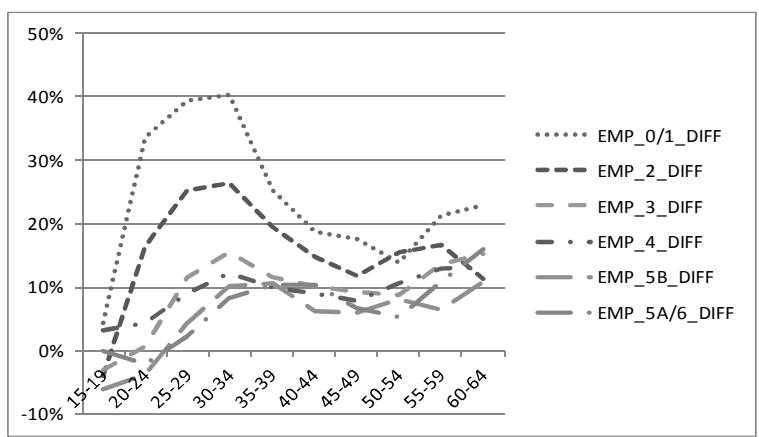

Employment rates for women

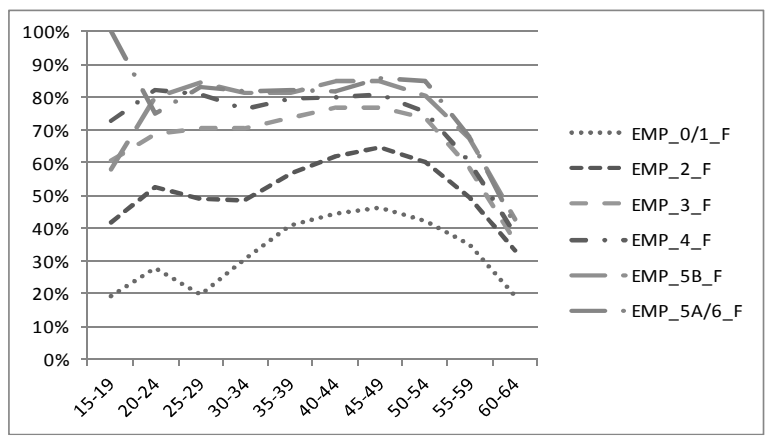

Survival rates of men and women

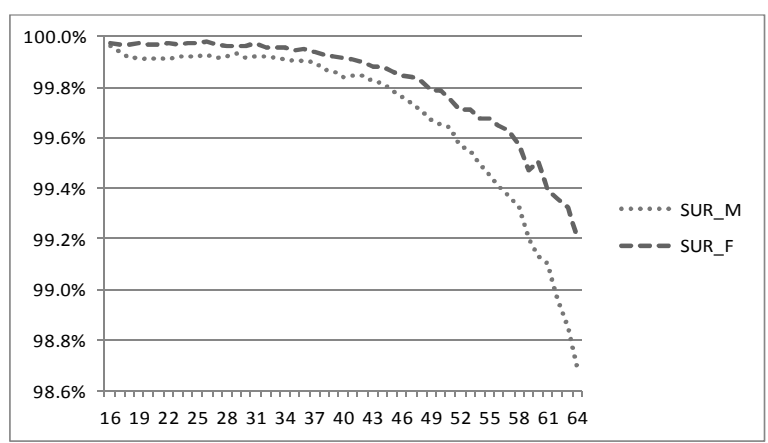

Source: OECD human capital project.

\section{2. $\quad$ Annual incomes and lifetime incomes}

84. Earnings profiles by age and educational attainment have been computed separately for men and women, and are based on the two concepts of annual income and lifetime income, respectively. Figure 3 presents estimates for Canada in 2006; the upper panels refer to annual incomes and the lower panels to lifetime incomes. These age-earnings profiles for Canada are similar to those prevailing in other countries covered by the project and to those highlighted in a range of national studies (e.g. Le et al., 2006; Liu and Greaker, 2009; Wei, 2004, 2007). In particular:

- Both annual and lifetime incomes rise with age and then gradually decline, a pattern that holds for all educational levels. The peaks occur at younger ages for lifetime income than for annual income.

- Both annual and lifetime incomes are higher for people with higher levels of educational attainment.

- Both annual and lifetime incomes are higher for males than for females, at all levels of educational attainment. 
Figure 3. Earnings profile for Canada in 2006

Current prices, in thousands Canadian dollars
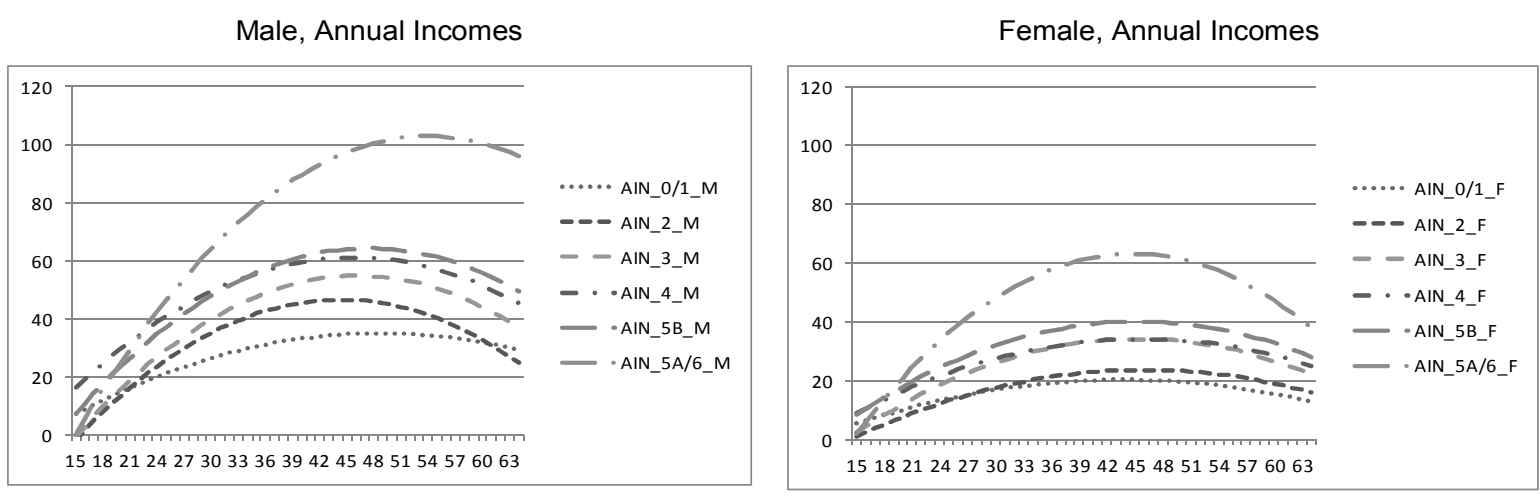

Male, Lifetime Incomes

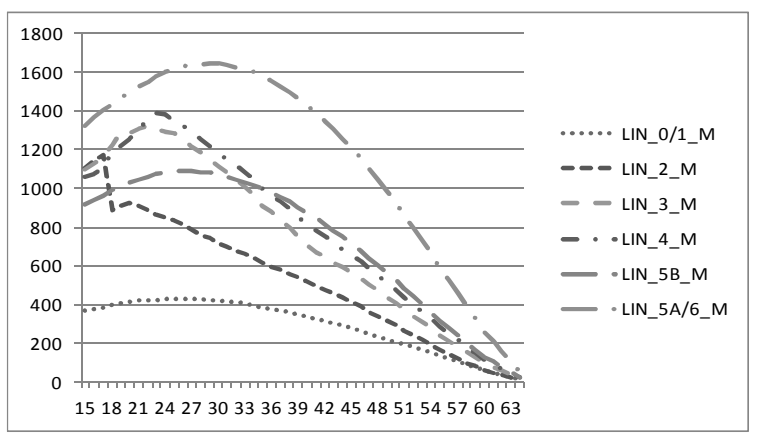

Female, Lifetime Incomes

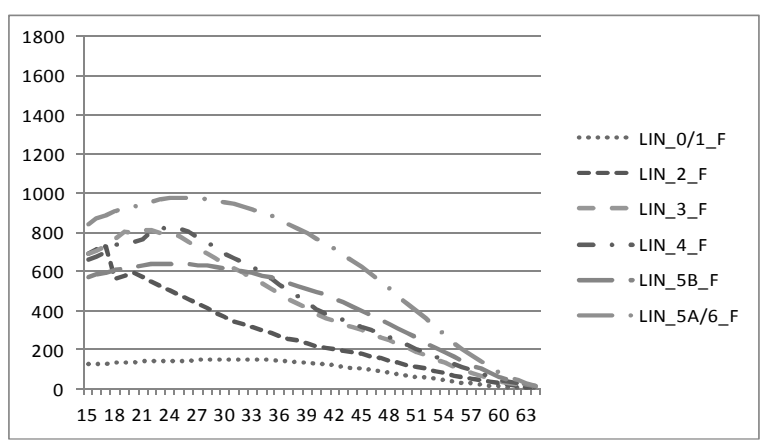

Source: OECD human capital project.

\subsection{Value of human capital}

\subsubsection{Level}

85. To give an indication of the magnitude of the stock of human capital estimated by using the lifetime income approach, panel a of Figure 4 shows the ratios between the value of the total stock of human capital and nominal GDP in $2006 .{ }^{25}$ The ratios range between 8.3 in the Netherlands and 16.3 in Korea, with an average value of around 10.6. Cross-country differences are smaller when ignoring the four countries at both ends of the distribution (i.e. the Netherlands and Italy, at the lower end; and Poland and Korea, at the higher end), ranging between 9 and 11 .

25. For Norway, GDP data shown in Figure 4 (as well as per capita GDP in Figure 8 and 9) refers to "GDP Mainland Norway", i.e. GDP exclusive the oil and ocean transport industries. 
Figure 4. Stock of human capital relative to GDP and to the stock of physical capital, 2006

Panel a. Stock of human capital to GDP

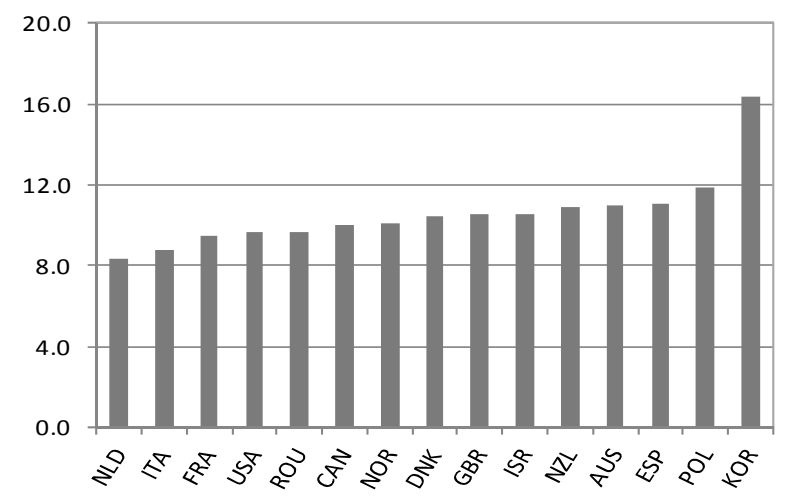

Panel b. Stock of human capital to physical capital

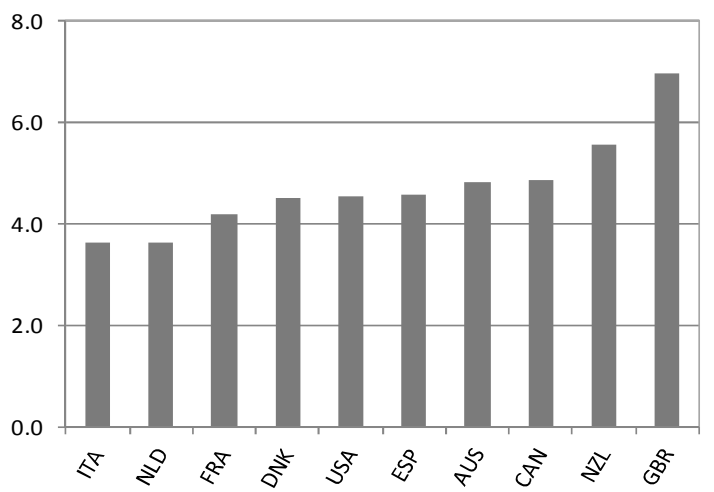

Note: Estimates for Australia refer to 2001, those for Denmark to 2002.

Source: OECD human capital project.

86. A second important feature highlighted by panel $\mathrm{b}$ of Figure 4 is that the monetary value of the stock of human capital based on the lifetime income methodology is typically several times larger than that of conventional economic capital in all countries for which relevant estimates of the latter are available. ${ }^{26}$ The data shown in Figure 4 indicate that ratios between human and physical capital range between 3.6 in the Netherlands and Italy and 7.0 in the United Kingdom, with a mean value of 4.7.

87. For some countries, the estimates of the stock of human capital based on the lifetime income approach described in this paper can be compared with estimates derived from national studies that used a similar methodology. To allow more meaningful comparisons, the project estimates provided below have been based on assumptions that are as close as possible to those used by the selected national studies. For instance, comparisons are based on the same values for annual real income growth rate and discount rate as those used in the corresponding national studies.

- In the case of Norway, the differences between the estimates computed for this project and those presented in Liu and Greaker (2009) range between 1\% (in 2001 and 2006) and 21\% in 2003, with an average difference (across the period) of $8 \%$.

- In the case of Australia, the difference relative to the results shown in Wei (2004) is about $-2 \%$ (in 2001).

- In the case of New Zealand, the difference relative to the results shown in Le et al (2006) is higher, at about $30 \%$ for 2001 .

26. The estimates of physical capital stock are drawn from OECD calculations based on investments data from member countries' National Accounts data. These estimates are net figures as opposed to the gross estimates of human capital reported in this project, i.e. living or human maintenance costs have not been deducted. There exist different views on whether these costs should be netted out from the gross estimates of human capital (e.g. Graham and Webb, 1979; Conrad, 1992). Another closely linked but different concern is that the gross estimates of human capital do not take into account the depreciation of human capital, such as deterioration in health and obsolescence of knowledge and skills (Conrad, 1992); however, one may argue that these factors are implicitly reflected in the wages rates paid to individuals used in this approach (Fraumeni, 2011b). 
- In the case of the United States, Christian (2010) shows human capital values (limited to market earnings) for the whole population (age 0 - 80) in 2006 of USD 212 trillion. The estimate presented in this paper, limited to the working age-population (age 15-64), is USD 153 trillion, implying a ratio between the two estimates of around $72 \%$; this difference is fairly close to the ratio of the working-age population to the entire US population $(67 \%)$.

- In the case of Canada, estimates of human capital per capita for the total population, for men and for women reported by $\mathrm{Gu}$ and Wong (2009) for 2007 are C\$ 653,000, 795,000 and 511,000. These values compare to estimates in this project of C\$ $627,000,799,000$ and 453,000 in 2006, suggesting differences of $-4 \%, 0.5 \%$ and $-11 \%$, respectively.

88. To sum up, almost all national studies that have applied the lifetime income approach to measuring human capital share the same findings that the stock value of human capital is substantially larger than that of traditional economic capital. The estimates produced as part of the OECD project, which are based on less detailed data than those typically available in the case of country-specific studies, are also broadly comparable to those produced by national research in the subject (with the partial exception of New Zealand). ${ }^{27}$ Detailed differences between project and national estimates could be further investigated in the future.

\subsubsection{Distribution}

89. The estimates of the stock of human capital based on the lifetime income approach can also be compared across different groups of people within each country. The distribution of human capital across people classified by different dimensions within each country provides useful information for addressing issues related to inequality, poverty and social cohesion. Taking 2006 as an example, this section describes the distribution of human capital between men and women (Figure 5), among people with different educational attainment (Figure 6) as well as among different age groups (Figure 7) for the countries participating in the project.

90. To facilitate cross-country comparison, the detailed (but differentiated) educational categories available for each country have been re-classified into three main groups, i.e. "below upper secondary education" (denoted as EDU_0/1/2), "upper secondary education" (EDU_3/4) and "tertiary education" (EDU 5/6). Data on individuals by single year of age have also been re-classified into three age groups, i.e. young people (i.e. those aged 15 to $34, \mathrm{AGE}_{-}$), prime-age people (those aged 35 to 54, AGE_II) and older people (those aged 55-64, AGE_III).

91. For each figure, the upper panel on the left shows the distribution of the population among the various groups, while the upper panel on the right shows the share of human capital accruing to the groups considered. The lower panel on the left shows the ratios between the shares of human capital accruing to each group and their corresponding population share (with ratios larger than 1 implying that the group considered is "rich" in human capital, and with higher ratios indicating that the more better off the corresponding group is in terms of its holdings of human capital). Finally, proxy estimates of the Gini coefficient based on grouped data (computed on the basis of Lorentz curves plotting shares of the

27. In addition to these countries, unpublished estimates of the stock of human capital for Israel (based on monthly income across four educational levels for the years 1997-2007), elaborated by the national statistical office of that country, are also similar to our estimates presented in this paper. 
population against shares of their human capital) are reported in the lower panel on the right of each figure. $^{28}$

92. Figure 5 provides information on the distribution of human capital between men and women in 2006. Although the population shares for men and women are in general very similar to each other (marginally higher in some countries and marginally lower for others, upper panel on the left), men dominate women in terms of their human capital holdings in all countries. This pattern is also confirmed by a visual inspection of the lower panel on the left of Figure 5.

93. In almost all countries, men account for more than $60 \%$ of the total value of the human capital stock, with Korea, Italy and the Netherlands recording values closer to, or higher than, $70 \%$. The exceptions are Romania and Poland, where men account for marginally less than $60 \%$ of human capital. Estimates of the Gini coefficient by gender vary between less than 0.10 to above 0.20 in Korea.

94. These gender differences in the distribution of human capital reflect a combination of lower labour force participation, lower employment and lower wages for women than for men. As women usually do more housework than men, these gender differences in human capital would be lower if human capital estimates were to be extended to include non-market activities.

28. The Gini coefficient is a measure ranging between 0 (in the case of perfect equality, i.e. the share of human capital accruing to each group is equal to its population share) and 1 (in the case of maximum inequality, e.g. all the human capital accrue to the richest group). While Gini coefficient is generally based on individual records (with each person ranked according to their income or wealth level), the values shown here are based on broad categories that ignore within-group inequality. 
Figure 5. Distribution of human capital by gender in 2006
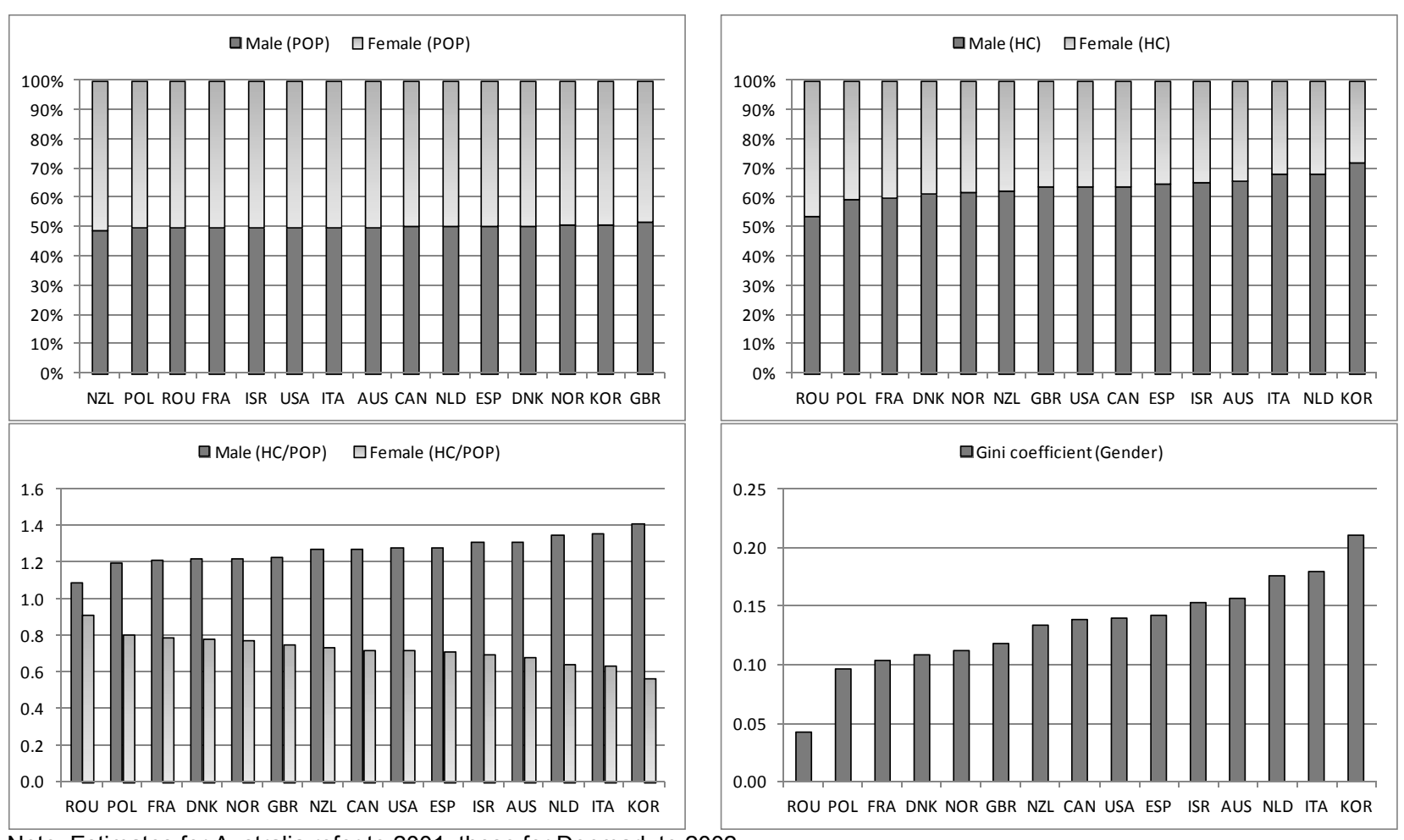

Note: Estimates for Australia refer to 2001, those for Denmark to 2002.

Source: OECD human capital project.

95. Figure 6 provides information on the distribution of human capital among people in the three main educational categories. In general, the higher the educational attainment of each person is, the higher will be their earnings and probability of having a job, and thus their measured human capital. However, because marginal returns to higher education (from EDU_0/1/2 to EDU_3/4 and from EDU_3/4 to EDU_5/6) vary across countries, human capital distribution by education varies as well. For instance, compared with other countries, the share of human capital held by more educated people is relatively low in Denmark and New Zealand, while it is relatively high in Italy and Spain. Estimates of the Gini coefficient by educational level range between less than 0.1 in Denmark, New Zealand, Poland and Canada and above 0.2 in Italy.

96. In theory, higher marginal returns from higher education are desirable since they provide incentives for people to augment their investments in human capital. In this sense, larger Gini coefficients may imply that investment in human capital is encouraged. But higher Gini coefficients by educational attainment may also signal constraints in the possibility to access or complete higher education, which would point to the need for remedial policies in this field. 
Figure 6. Distribution of human capital by educational level in 2006
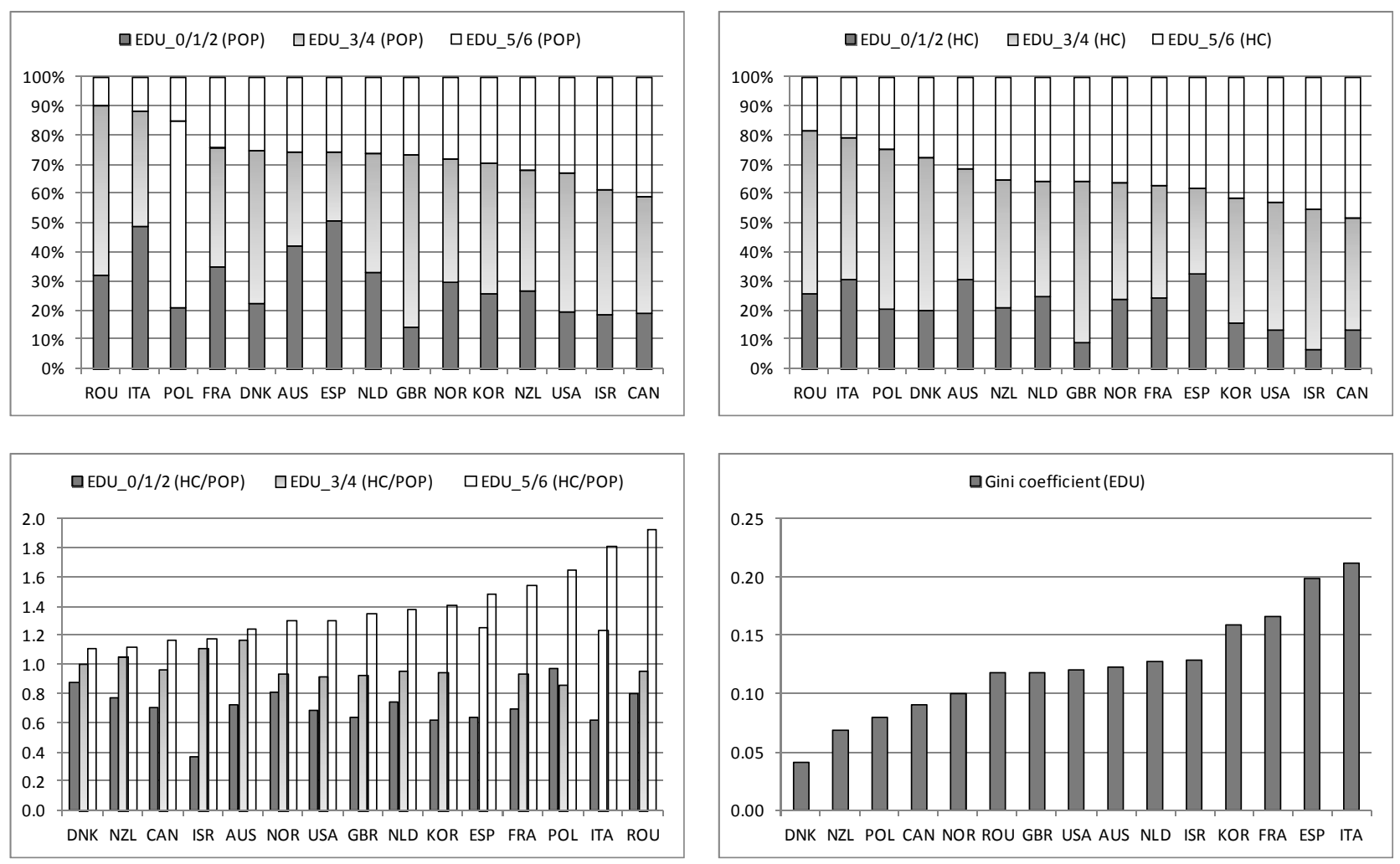

Note: Estimates for Australia refer to 2001, those for Denmark to 2002.

Source: OECD human capital project.

97. Finally, Figure 7 shows the distribution of human capital by age groups. The methodology used in this paper implies that the younger people are the more human capital they hold. The reason is that younger people have a longer remaining lifetime than their older counterparts, an effect that more than offsets their lower annual income compared to seniors. Conversely, higher unemployment rates for youths tend to lower the chance of their human capital to be employed in economic activities, implying that reducing youth unemployment rates is important not only to improve the current situation of youths but also to increase a country's (realized) human capital stock. ${ }^{29}$

29. The youth employment rate figures are selected among the four human capital leading indicators by The Lisbon Council (Ederer, et al., 2011). 
Figure 7. Distribution of human capital by age group in 2006
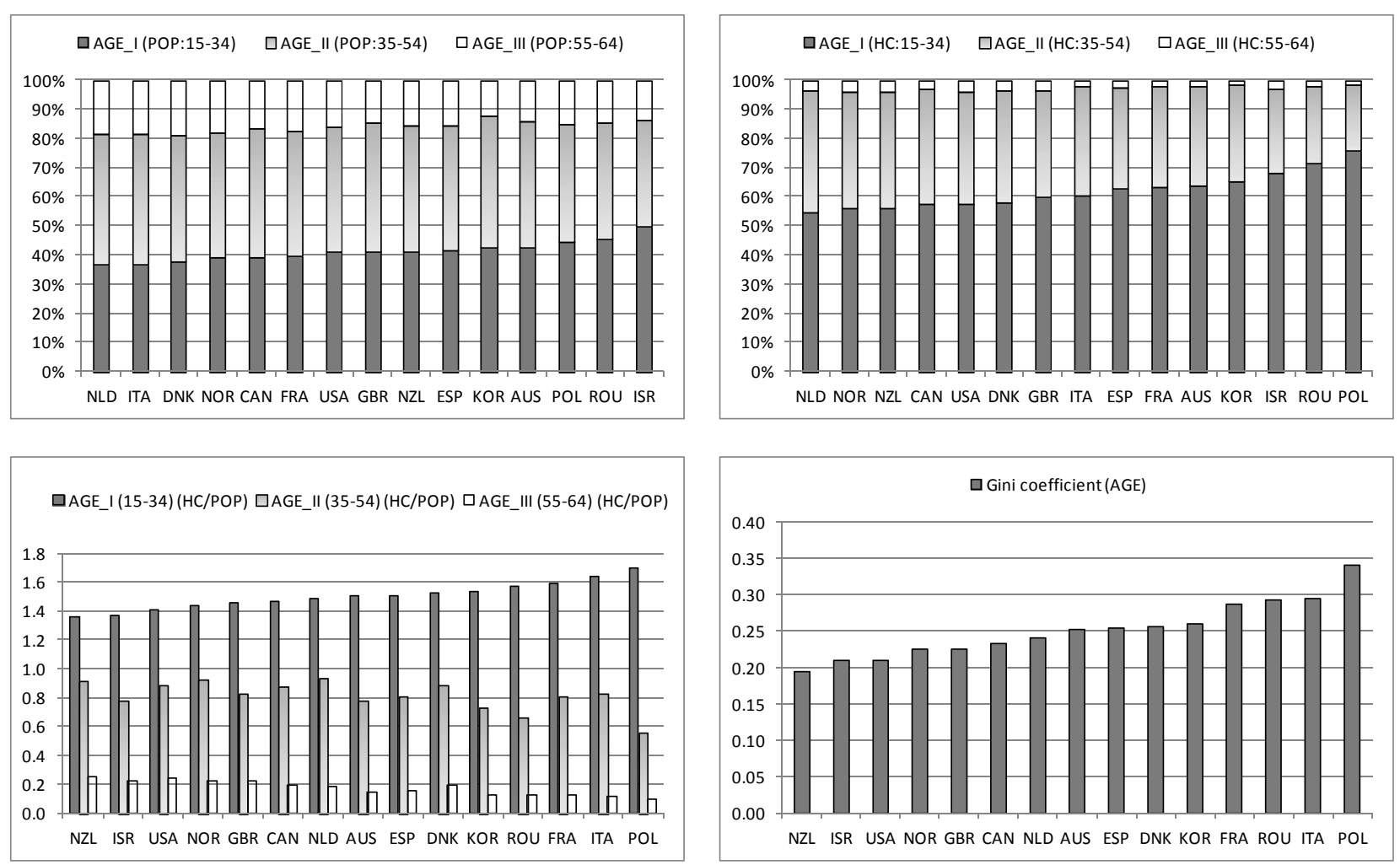

Note: Estimates for Australia refer to 2001, those for Denmark to 2002.

Source: OECD human capital project.

98. One obvious limit of the methodology used in this paper is that youths, as they age, are assumed to achieve the same earnings and employment probabilities of today's prime aged workers. To the extent that this assumption does not hold true (i.e. that today's youths could earn less as they age than prime-aged workers earn today), the human capital holdings of young people will turn out to be much worse than depicted here.

\subsection{Volume measures of the stock of human capital}

\subsubsection{Spatial volume index}

99. County comparison based on the total value of human capital may be misleading due to two factors: first, because countries have different population sizes; and second, because countries may differ in terms of the purchasing power of people's earnings. Figure 8 addresses these two factors by showing information on countries' human capital values per capita in 2006. To take into account differences in price levels across countries, the estimates shown here are based on purchasing power parities (PPPs) for private consumption in each country, and expressed in terms of USD. 
Figure 8. Real human capital per capita in 2006

Thousands of USD
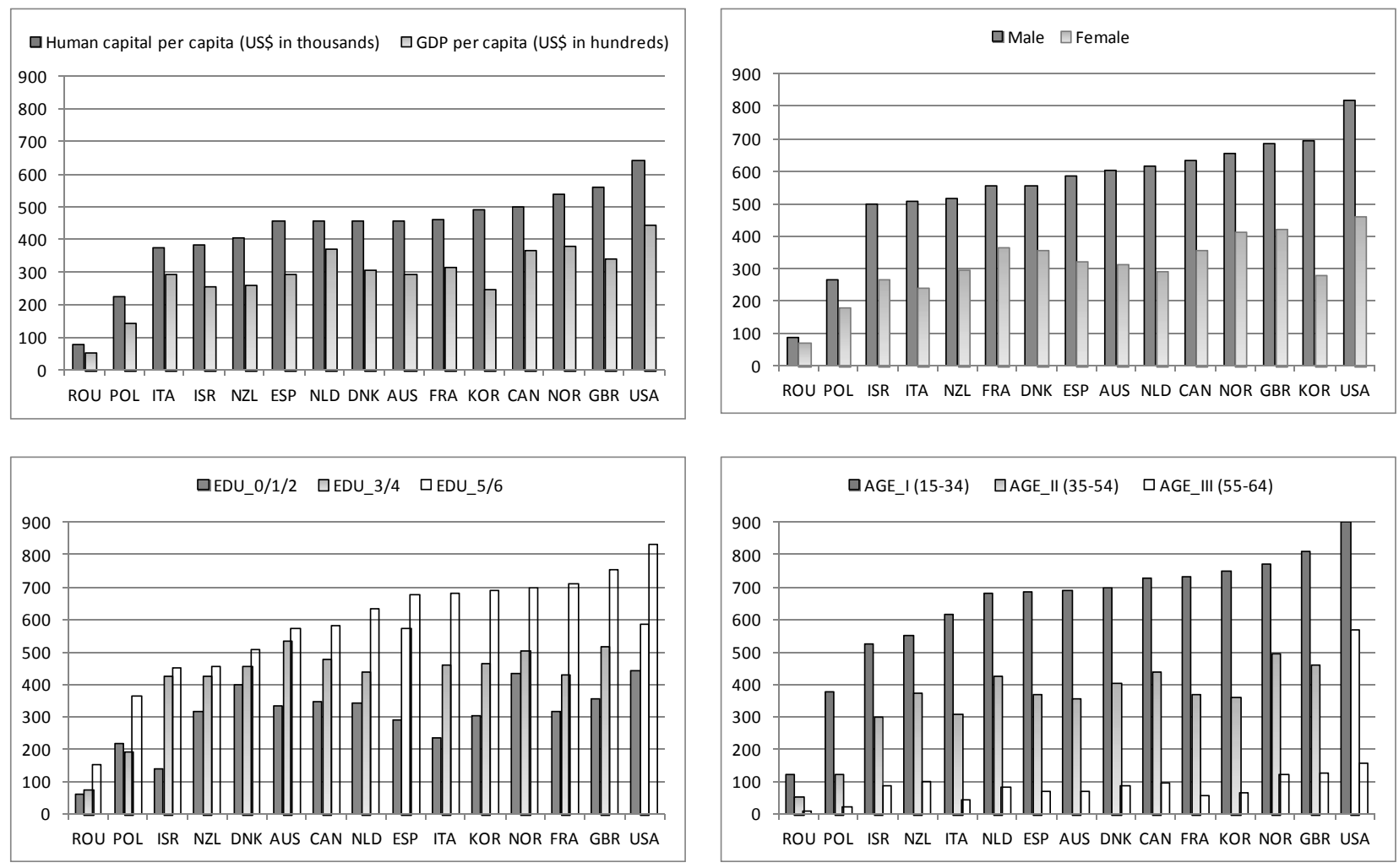

Note: Estimates for Australia refer to 2001 and for Denmark to 2002.

Source: OECD human capital project.

100. Based on the assumptions made here on the annual real income growth rate and discount rate, the estimates shown in Figure 8 indicate that the values of human capital per capita range between USD 79,000 in Romania and USD 641,000 in the United States. Excluding the two ends of the distribution (Romania and Poland, at the lower end, and the United Kingdom and the United States, at the higher end), the differences of human capital per capita among other countries are, however, relatively small, comprised in a range between around USD 400,000 and USD 550,000.

101. For the purpose of country comparisons, values of GDP per capita in USD are also presented in the left upper panel of Figure 8. Broadly speaking, countries with a higher GDP per capita also display a higher value of human capital per capita, but there are exceptions. For instance, despite relatively high GDP per capita in Italy and the Netherlands, their human capital per capita is relatively low. Conversely, Korea combines comparatively low GDP per capita and higher human capital per capita than most other countries.

102. Holdings of human capital per capita by gender, by educational level and by age groups are also shown in upper-right, lower-left, and lower-right panels of Figure 8, respectively. Country-rankings in these panels are broadly similar to those shown for human capital per capita in upper-left panel in the same figure. Nevertheless, due to differences in how human capital is distributed in various countries, the rankings are not exactly the same. 
103. An alternative way of presenting the same type of information is conveyed by Figure 9, which shows country volumes of human capital per capita in 2006 relative to the level observed in the United States (set equal to 100). The upper left panel of Figure 9 shows that the volume index of human capital per capita is only 12 for Romania and of 38 for Poland, and over 60 for most other countries. This means that human capital per capita is larger in the United States than in any other participating countries. The same conclusion can be drawn from the other panels in Figure 9 when looking at various population groups.

Figure 9. Human capital spatial volume indices in 2006

US levels equal to 100
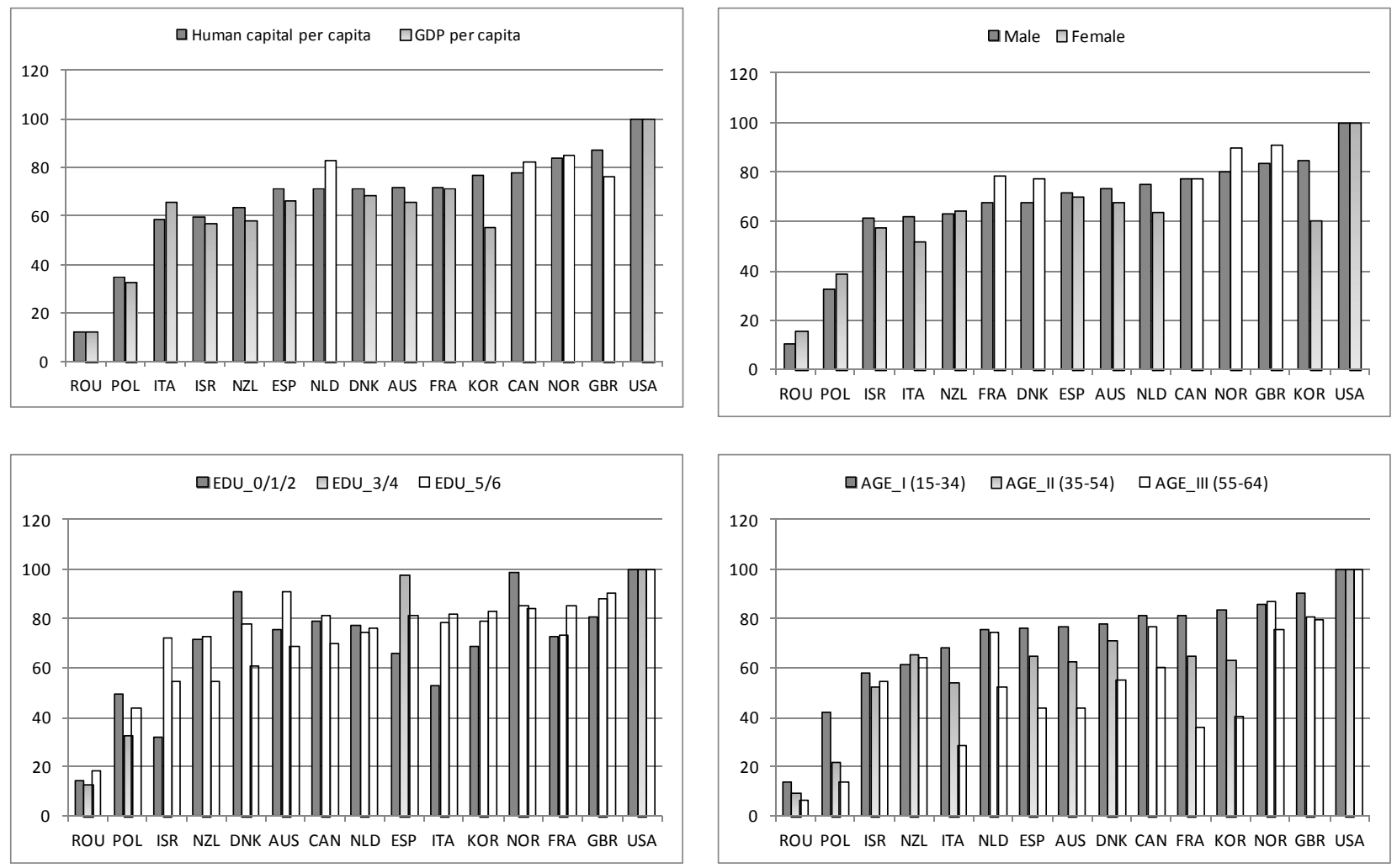

Note: Estimates for Australia refer to 2001, those for Denmark to 2002.

Source: OECD human capital project.

\subsubsection{Temporal volume index}

104. Information on how the stock of human capital in volume terms evolves in a country is of critical importance for policy decisions. In particular, from the perspective of assessing sustainability, a necessary condition for a country to grow along a sustainable path is that the volume of its total capital stock in per capita terms should not decline over time (UNECE, 2009). While this argument underscores the importance of having a single measure of how the total capital stock of each country evolves over time (in real terms), information on the volume changes in per capital stocks of different types of capital is also important.

105. Though the observation of declining levels of human capital per capita would not necessarily imply that the development path for the country in question is "unsustainable", since this decline in human 
capital could be offset by raising stocks of other types of capital (as implied by the "weak sustainability" criterion, according to which different types of capital are assumed to be substitutable for each other, (Pearce and Atkinson, 1993)), nonetheless a decline in the real stock of human capital per capital will warrant policy attention.

106. Moreover, this argument is even more justified when applying the "strong sustainability" criterion, according to which critical capitals should not be allowed to fall below some minimum levels (Pearce and Atkinson, 1993).

107. Figure 10 displays information on human capital temporal volume indices (denoted as "VOL"), population indices ("POP") and human capital per capita indices ("HCPERCAPITA") for participating countries during their corresponding observation years. ${ }^{30}$ For each country, the volume of human capital in the base year was set as equal to 100 .

108. Compared with the starting year, the total stock of human capital in real terms has increased for all countries, though there were ups and downs for a few countries throughout the observation period. Even for countries that experienced increasing human capital volumes throughout the period, however, the rate of increase varied significantly across these countries.

30. Due to data constraint, Figure 10 shows human capital temporal volume indices only for 12 OECD countries. 
Figure 10. Human capital temporal volume indices

Australia

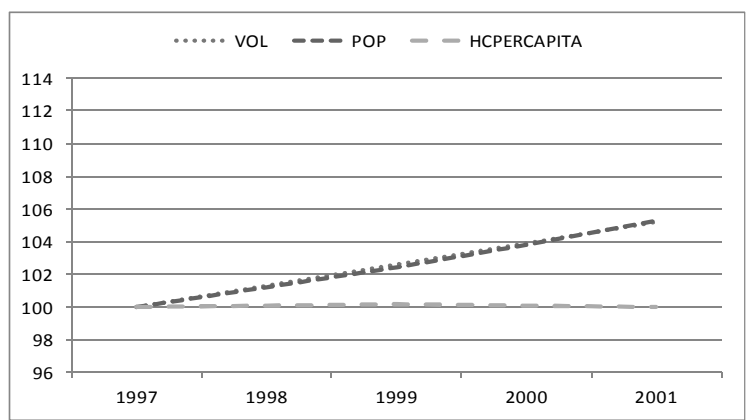

France

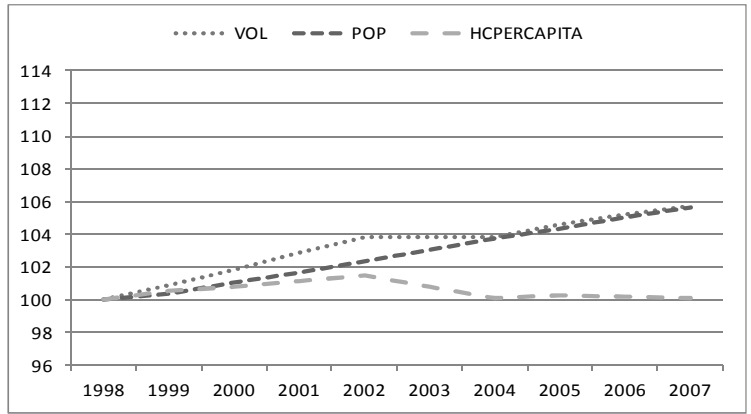

Italy

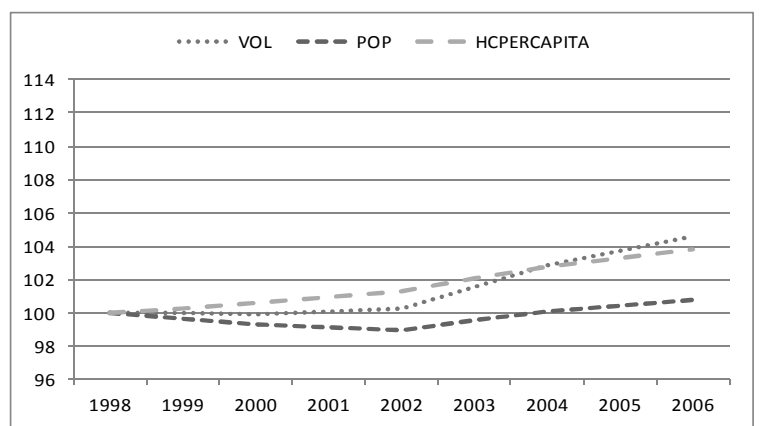

Canada

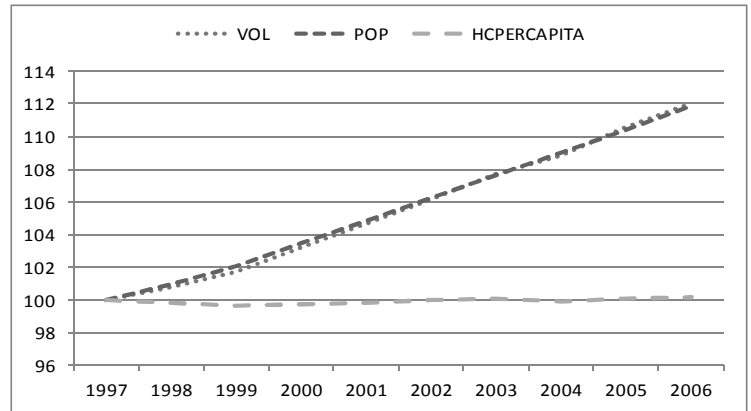

Israel

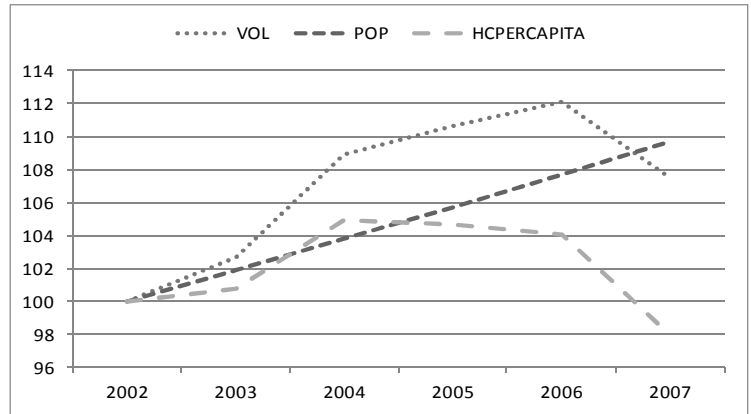

Korea

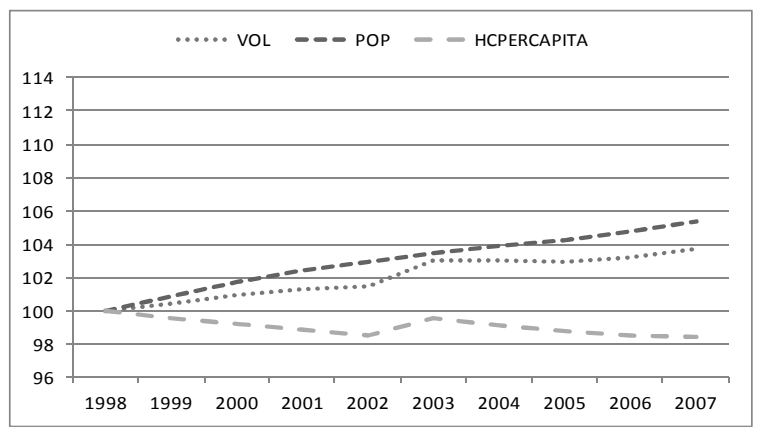


Figure 10. Human capital temporal volume indices (continued)

New Zealand

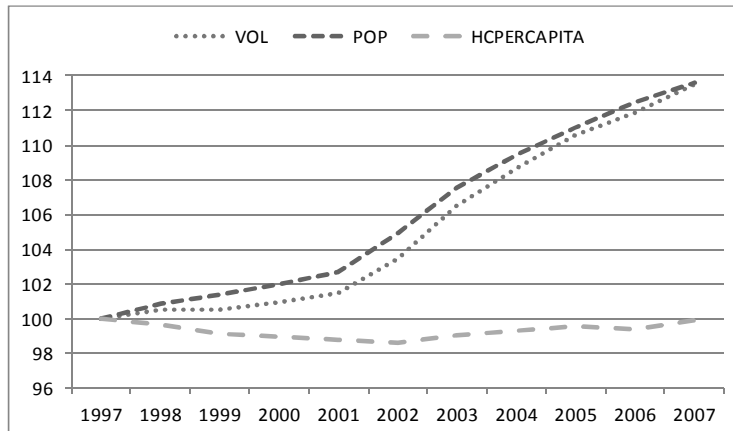

Poland

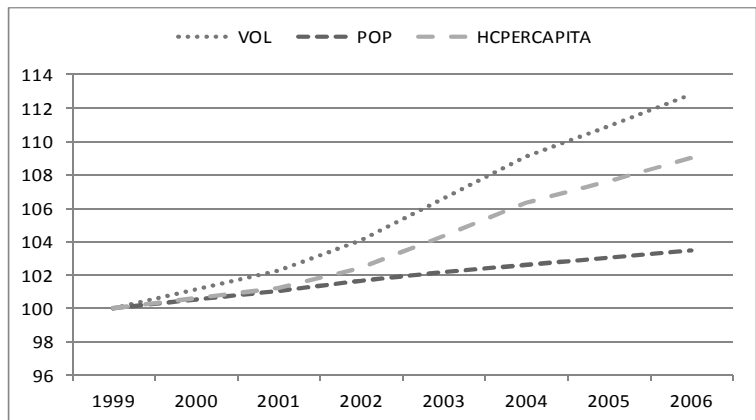

United Kingdom

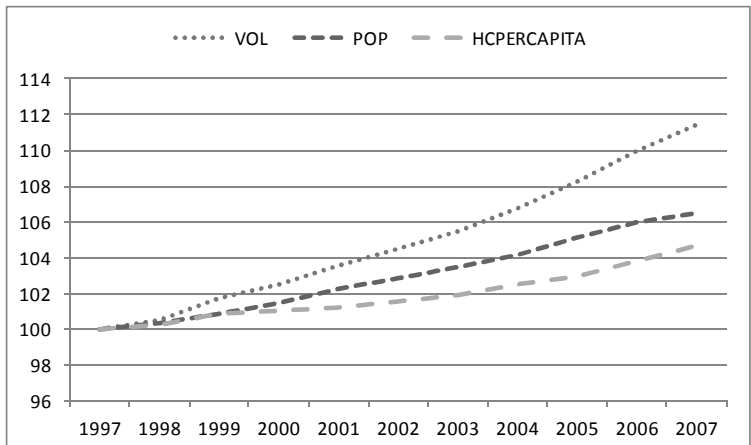

Norway

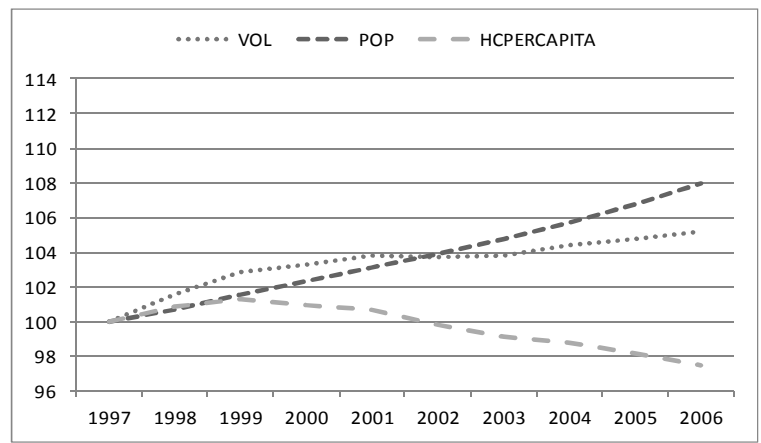

Spain

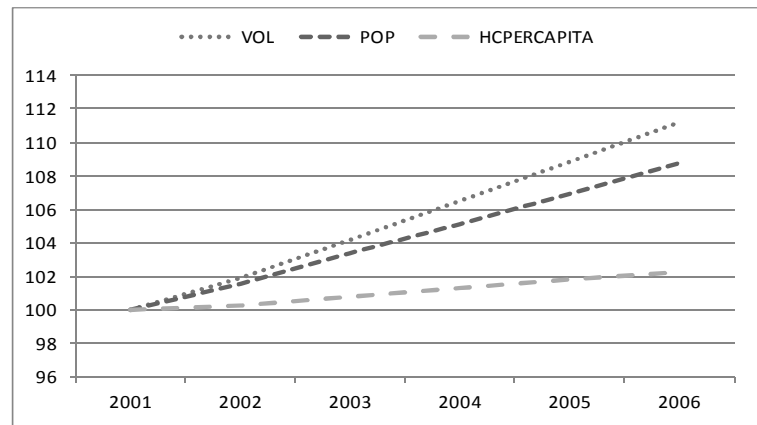

United States

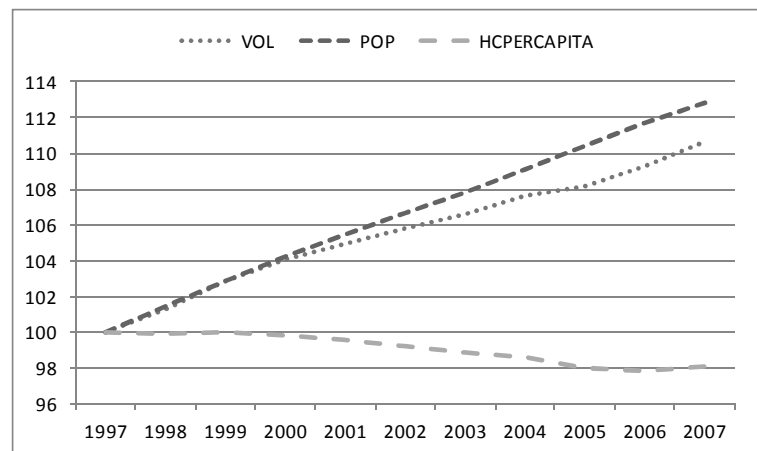

Note: The abrupt fall of human capital volume from 2006 to 2007 in Israel reflects a change of educational categories. Source: OECD human capital project.

109. The situation is strikingly different when looking at changes in the volume of human capital per capita. With the exception of Italy, all countries experienced growing population during the period. The difference of the growth rate of human capital volumes index and that of population is the growth rate of human capital per capita. Relative to its starting year, three patterns are in evidence:

- Higher human capital volumes per capita in Italy, Poland, Spain and the United Kingdom;

- Broadly stable human capital volumes per capita in Australia, Canada, France and New Zealand; 
- Lower human capital volumes per capita in Israel, Korea, Norway and the United States.

110. To explore why human capital volumes per capita increased in some countries and declined in others, decomposition analyses can be used. Partial volume indices allow assessing the relative importance of the various factors at work. As outlined in Section 2.4.2.2, these partial volume indices refer to the main population characteristics (i.e. age, gender and educational attainment) and allow examining the contribution of these characteristics to the real growth of human capital per capita.

111. Figure 11 provides information on average annual growth rate of human capital per capita for each country throughout the observation period available (shown as "diamonds" in the figure). Contributions from first-order partial indices with respect to age, gender and educational level are reported in the form of stacked bars: as mentioned already, the sum of the contribution that each characteristic makes to the growth of human capital per capita will not equal the overall growth in human capital per capita, as these contributions represent only first-order approximations.

Figure 11. Decomposition of average annual growth of human capital volumes per capita due to age, gender and educational attainment

First-order partial volume index, percentages

$\square$ Age $\square$ Education $\square$ Gender $\diamond$ HCper capita

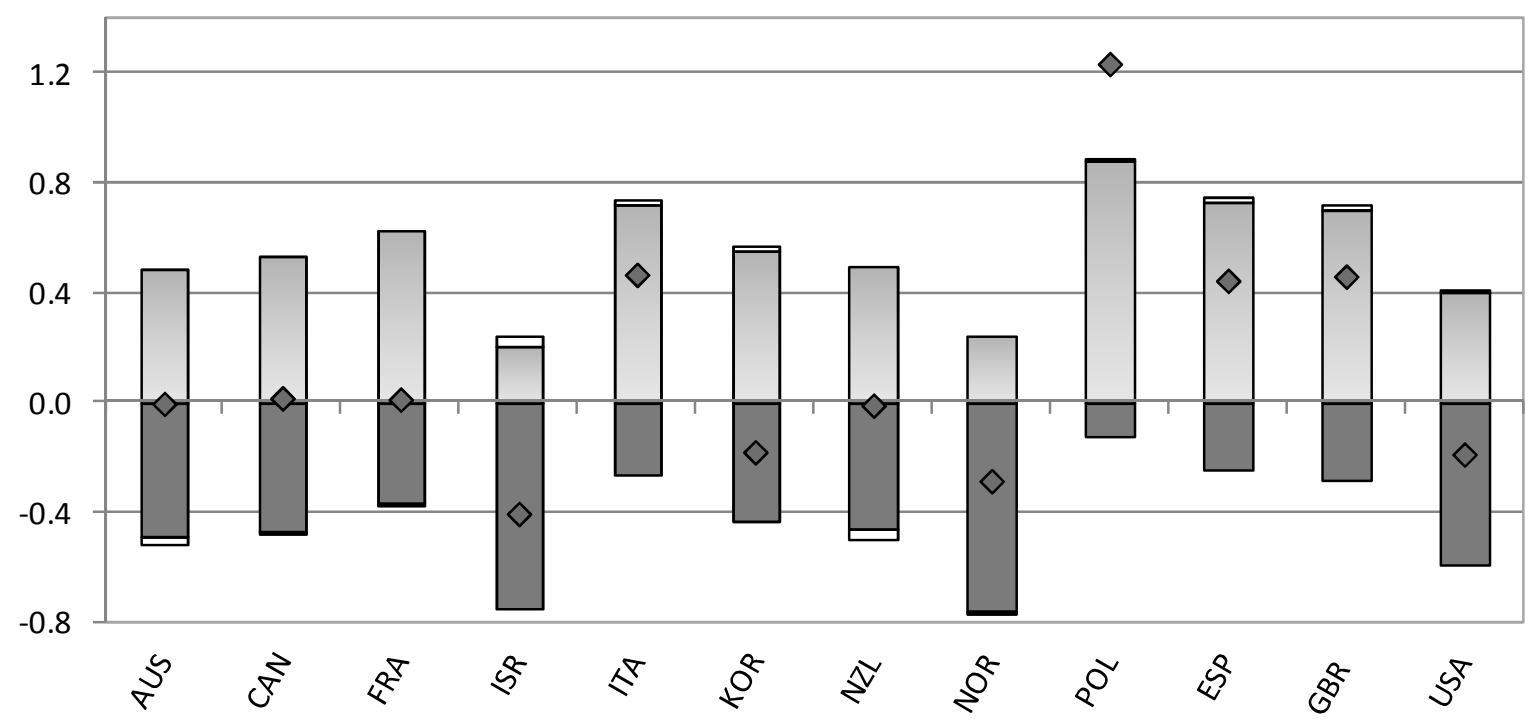

Note: The period considered for each country corresponds to the beginning and ending year shown in Table 1. For many countries, the contribution from gender is too small to be discernable in the figure.

Source: OECD human capital project.

112. Figure 11 indicates that, compared with the contributions from other two characteristics, the contribution of shifts of the population between gender was very small (positive for Israel, Italy, Korea, Poland, Spain, the United Kingdom and the United States; negative for Australia, Canada, France, New Zealand and Norway) and almost negligible for all countries. This means that during the observation period shift of population composition between men and women had little effect on the change of human capital per capita for all countries. 
113. Similarly, for all countries the contribution from educational level was positive while that from age was negative. The former effect suggests that, during the period, more people attained higher levels' education; while the latter signals that all countries were experiencing population ageing (since older people have fewer remaining working years and thus lower lifetime income). ${ }^{31}$

114. The magnitude of these two opposite effects varied across countries. For countries that experienced increased volumes of human capital per capita (Italy, Poland, Spain and the United Kingdom), the positive contribution from education was larger than the negative effect from population ageing. For countries that experienced broadly stable volumes of human capital per capita (Australia, Canada, France and New Zealand), these two effects almost cancelled out with each other. Finally, for countries that experienced decreased volumes of human capital per capita (Israel, Korea, Norway and the United States), the contribution from age exceeded that from education. ${ }^{32}$

115. One obvious policy implication that can be drawn from these patterns is that some countries are not investing enough in education to offset the negative effect of population ageing.

\subsection{Sensitivity analysis}

116. The estimates of human capital presented in this project are subject to a number of assumptions, in particular assumptions about two key parameters, i.e., the annual growth rate of real earnings of each age/gender/education categories in the future; and that on the discount rate. A number of national studies have shown that human capital estimates based on the lifetime income approach are sensitive to the choice of these two parameters (e.g. Wei, 2004; Gu and Wong, 2008, 2009; Liu and Greaker, 2009; Fraumeni, 2011a).

117. In this project, sensitivity analysis has been implemented with respect to these two parameters. Taking the United States as an example, Table 2 shows results of sensitivity analyses on human capital stock value and its distribution in 2006. In Table 2, the baseline scenario is one where the annual real income growth rate is set at $1.30 \%$ and the discount rate is $4.58 \%$, the values used for generating the estimates of human capital for the United States that have been shown above.

31. Recall that the focus of the current study is the working age (15-64) population. An ageing working age population implies that the share of elderly people is increasing relative to that of younger people. This could happen when more prime age people (35-54) become older (55-64) and/or when less younger people (aged less than 15 years) enter the working age population.

32. Korea, a country where the contribution from education was larger than that from age, is an exception. This might reflect the fact that Korea is the only country that combines educational Level 4 with Level 5B in the original data source. As a result, the tertiary educational level (EDU_5/6) used for Korea in this project includes Level 4; one consequence is that the contribution from first-order volume index with respect to education might be exaggerated. 
Table 2. Sensitivity analysis on human capital stock value and distribution for the United States in 2006

\begin{tabular}{|c|c|c|c|c|c|c|c|c|c|c|}
\hline \multirow{3}{*}{$\begin{array}{c}\text { Fixed } \\
\text { annual } \\
\text { discount } \\
\text { rate }(4.58 \%)\end{array}$} & \multirow{3}{*}{$\begin{array}{c}\text { Annual } \\
\text { income } \\
\text { growth } \\
\text { rate }(\%)\end{array}$} & \multirow{3}{*}{$\begin{array}{c}\begin{array}{c}\text { Level } \\
\text { (trillions) }\end{array} \\
\text { Total } \\
\text { stock }\end{array}$} & \multicolumn{8}{|c|}{ Distribution (\%) } \\
\hline & & & \multicolumn{2}{|c|}{ Gender } & \multicolumn{3}{|c|}{ Education } & \multicolumn{3}{|c|}{ Age } \\
\hline & & & Males & Females & EDU_0/1/2 & EDU_3/4 & EDU_5/6 & AGE_I & AGE_II & AGE_III \\
\hline Baseline & 1.30 & 128,235 & 63.8 & 36.2 & 13.4 & 43.7 & 42.9 & 57.6 & 38.5 & 3.9 \\
\hline Scenario_A & -2.10 & $\begin{array}{l}86,131 \\
(-32.8)\end{array}$ & $\begin{array}{c}63.7 \\
(-0.2)\end{array}$ & $\begin{array}{l}36.3 \\
(0.3)\end{array}$ & $\begin{array}{c}11.2 \\
(-16.4)\end{array}$ & $\begin{array}{c}42.4 \\
(-3.0)\end{array}$ & $\begin{array}{l}46.4 \\
(8.2)\end{array}$ & $\begin{array}{c}50.6 \\
(-12.2)\end{array}$ & $\begin{array}{c}44.1 \\
(14.5)\end{array}$ & $\begin{array}{c}5.3 \\
(35.9)\end{array}$ \\
\hline Scenario_B & 1.11 & $\begin{array}{c}125,099 \\
(-2.4)\end{array}$ & $\begin{array}{l}63.8 \\
(0.0)\end{array}$ & $\begin{array}{l}36.2 \\
(0.0)\end{array}$ & $\begin{array}{c}13.3 \\
(-0.7)\end{array}$ & $\begin{array}{c}43.6 \\
(-0.2)\end{array}$ & $\begin{array}{l}43.2 \\
(0.7)\end{array}$ & $\begin{array}{c}57.2 \\
(-0.7)\end{array}$ & $\begin{array}{l}38.8 \\
(0.8)\end{array}$ & $\begin{array}{c}4.0 \\
(2.6)\end{array}$ \\
\hline Scenario_C & 1.50 & $\begin{array}{c}131,673 \\
(2.7)\end{array}$ & $\begin{array}{l}63.8 \\
(0.0)\end{array}$ & $\begin{array}{l}36.2 \\
(0.0)\end{array}$ & $\begin{array}{l}13.5 \\
(0.7)\end{array}$ & $\begin{array}{l}43.8 \\
(0.2)\end{array}$ & $\begin{array}{c}42.7 \\
(-0.5)\end{array}$ & $\begin{array}{l}58.1 \\
(0.9)\end{array}$ & $\begin{array}{c}38.1 \\
(-1.0)\end{array}$ & $\begin{array}{c}3.8 \\
(-2.6)\end{array}$ \\
\hline Scenario_D & 3.96 & $\begin{array}{c}188,188 \\
(46.8)\end{array}$ & $\begin{array}{l}63.8 \\
(0.0)\end{array}$ & $\begin{array}{l}36.2 \\
(0.0)\end{array}$ & $\begin{array}{c}15.8 \\
(17.9)\end{array}$ & $\begin{array}{l}44.7 \\
(2.3)\end{array}$ & $\begin{array}{c}39.6 \\
(-7.7)\end{array}$ & $\begin{array}{c}64.1 \\
(11.3)\end{array}$ & $\begin{array}{c}33.0 \\
(-14.3)\end{array}$ & $\begin{array}{c}2.9 \\
(-25.6)\end{array}$ \\
\hline
\end{tabular}

Note: Changes (in percentages) relative to Baseline scenario are shown in parentheses.

Source: OECD human capital project.

118. Since income growth rate and discount rate enter the estimation of the stock of human capital in multiplicative forms (see equations 1 and 2 in Box 1), what matters is the ratio between the two parameters, i.e. $\{(1+r) /(1+\delta)\}$. For this reason, the four scenarios shown in Table 2 rely on the same annual discount rate $(4.58 \%$ for all scenarios) while differing in terms of the real income growth rate that they use (-2.1\% in Scenario A, 1.11\% in Scenario B, 1.50\% in Scenario C and 3.96\% in Scenario D), respectively; this implies setting the values of the parameter $\{(1+r) /(1+\delta)\}$ at $96.86 \%, 93.62 \%, 96.68 \%$, $97.05 \%$ and $99.41 \%$, respectively.

119. Table 2 shows that the estimates of the total value of the stock of human capital are sensitive to the choice of the two parameters. Nonetheless, the distribution of human capital between men and women, among educational groups and among age groups are less sensitive. Likewise, the growth of the volume of human capital is not very sensitive to the choice of the two parameters. As shown in Figure 12, the curves of human capital volume for Scenarios Baseline, B and C are almost identical; the same applies to the curves of human capital per capita. 
Figure 12. Sensitivity analysis on human capital temporal volume index for United States

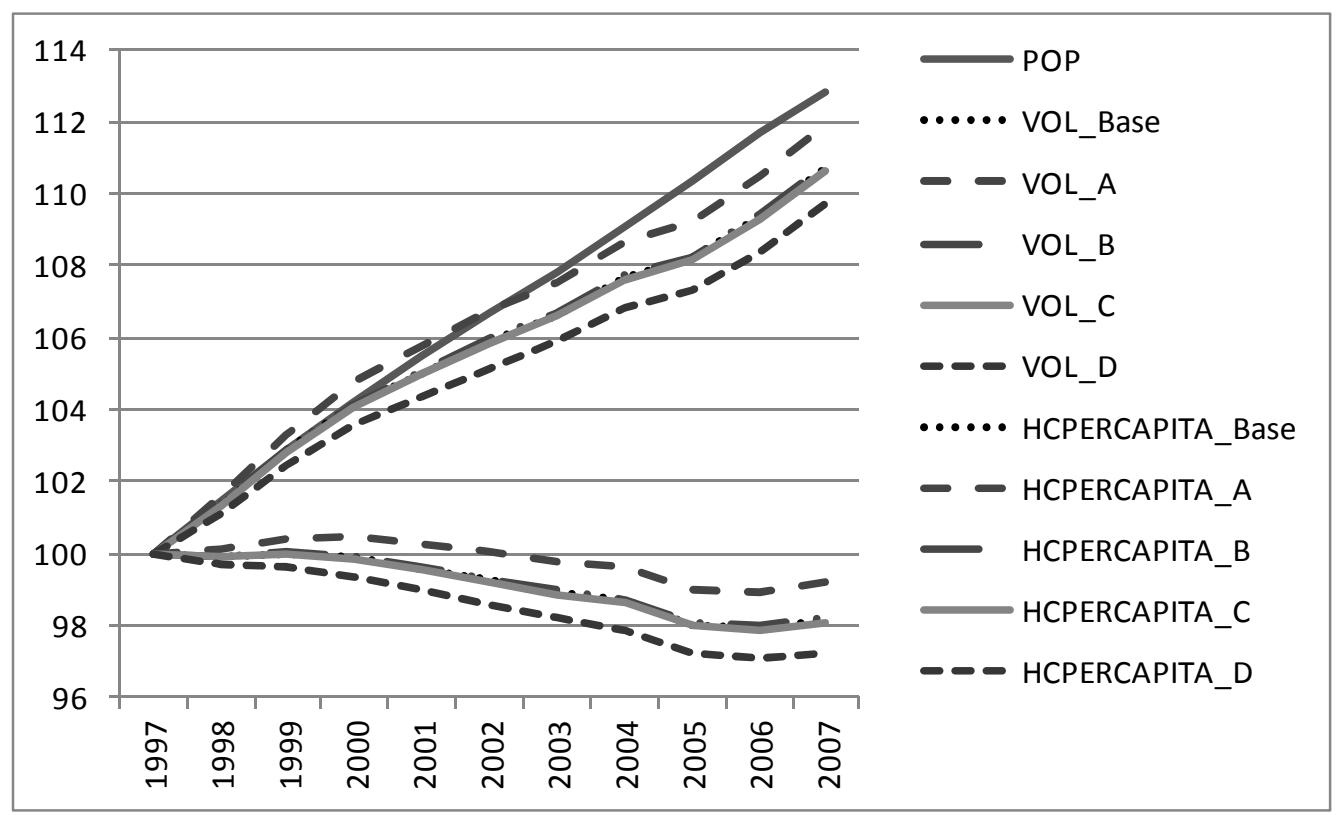

Source: OECD human capital project.

120. One interesting pattern from Figure 12 is that the curve referring to the volume of human capital in Scenario A, which relies on a lower income growth rate than in the Baseline, lies above that for the Baseline scenario; conversely, in Scenario D, which uses a higher income growth rate than in the Baseline, the curve for the volume of human capital is below that of the Baseline scenario. These counter-intuitive results reflect the nature of the method used to estimate lifetime income in this paper.

121. In terms of equations (4), (5) and (6), the higher-than-Baseline income growth rate (as in the case of Scenario D) implies a higher share for the value of human capital held by younger people than for their older counterparts. Due to the population ageing observed in the United States (and given that the sum of the value shares must equal one), the higher growth in the older population combined with a lower share of human capital held by this group, together with the lower growth in younger population weighted by a higher share of their human capital, lead to a growth of human capital volume that is smaller than in the Baseline.

122. In addition, although the level of human capital volume is increasing due to higher income growth rate, the curve of human capital volume will be shifted down in order to keep the volume level at the starting year (1997) fixed at 100.

123. Therefore, in Scenarios that have higher income growth rate than in the Baseline, the lower growth rate of human capital volume, combined with the fixed starting value, will lead to curves of human capital volume that lie below the curve for the Baseline. The opposite holds true for scenarios that have lower income growth rate (e.g. Scenario A) than in Baseline.

124. While this paradoxical results stem from equations (4), (5) and (6), together with the population ageing that is observed in the United States, it may also reflect a more fundamental constraint imposed by the basic assumptions made in this approach, i.e. that annual real income growth rate is exogenously given rather than derived from the model. The implications of this assumption can be gleaned when considering that, in a country experiencing ageing population, its long term economic growth would be affected since 
human capital, a critical asset for economic growth, is declining. This causal link from ageing population to future income growth rate is neglected in the model for human capital measurement used in this project. Exploring how population ageing will affect real income growth rate in the future is beyond the scope of this project.

\section{CONCLUSIONS AND NEXT STEPS}

125. Human capital is of significant importance for policy makers to address various issues such as economic growth, quality of life, social cohesion and sustainable development. The OECD Human Capital Project is among the first attempts to measure human capital for comparisons both across countries and over time. To that end, an OECD database has been constructed for most of the project participating countries, containing information on the various elements that enter the human capital estimation, based on the lifetime income approach.

126. The results contained in the paper show the feasibility of applying the lifetime income approach to measuring human capital for comparative analysis. They also highlight the feasibility of applying the methodology to categorical data (e.g. by 5 -year or 10-year age group) that are typically available within the OECD statistics system, rather than to more demanding detailed data that would be required by the original Jorgenson-Fraumeni methodology. The main results are as follows:

- Despite of some differences, most of the estimates in this paper are in line with those reported in national studies. In terms of the level of human capital value, almost all studies share the conclusion that, even when estimates are restricted to market activities, the value of human capital is substantially larger than that of traditional physical capital and is much larger than GDP (by a factor ranging from around eight to over ten times in this study).

- Within countries, the stock of human capital is not uniformly distributed across different groups of the population. The distributions of human capital indicate that men have a higher human capital than women. In addition, people with higher education are better off than those with lower education, and the same is true for younger people compared to their older counterparts, although the detailed patterns vary across countries.

- Adjusting for changes in price levels in each country shows that human capital volume increased for all countries during the observed period. However, in some countries, the volume of human capital in per capita terms fell.

- Decomposition analysis of human capital volume indices shows that changes in the structure of the population between men and women had little effect on the change of human capital per capita in all countries. While more people attaining higher levels' education contributed positively to the change of human capital per capita in each country, in all countries population ageing contributed negatively to this change over the observed years.

- The magnitude of these two opposite effects varied across countries. In Italy, Poland, Spain and the United Kingdom, the positive contribution from higher educational attainment exceeded the negative effect of population ageing, while the opposite was true in Israel, Korea, Norway and the United States. An obvious implication is that, when facing population ageing, countries should invest more into education so as to offset this negative demographic effect.

- Finally, the sensitivity analysis confirms that estimates of the values of human capital are sensitive to the choice of the two key parameters in the estimation, i.e. the annual real income 
growth rate and the discount rate. But within-country distribution of human capital and trends in human capital volume index in each country are less sensitive.

127. Country-specific assumptions of real income growth rates and a common discount rate have been used in this project to estimate human capital based on the lifetime income approach. Although there are reasonable arguments for these choices, there are also reasons in favour of different assumptions. This issue will have to be addressed in future research. ${ }^{33}$

128. In conclusion, it seems that, despite some deficiencies in the methodology used, the lifetime income approach, by bringing together the influence of a broad range of factors (demography, mortality, and educational attainment, as well as labour market aspects) allows comparing the relative importance of these factors and drawing useful policy implications from the estimates.

129. In the near term, the project could be expanded in two main directions: (i) improving the underlying statistical information (e.g. by using information from other sources to improve current data on school enrolment rates, by improving the comparability of educational categories, by improving the earnings concept used in the OECD database); and (ii) extending the work to additional countries and years.

130. In the longer term, the OECD work on human capital based on the lifetime income approach could explore a number of more fundamental issues, including:

- Running simulations of future stocks of human capital, based on existing demographic projections.

- Constructing human capital accumulation accounts that will help explain changes in the stock of human capital over time in terms of investment, depreciation and revaluation.

- Using the human capital estimates to construct an education satellite account, combining various inputs and outputs data on education.

- Extending the scope of the current accounting exercise to include children (below age 15), the elderly (above 65) and non-market activities.

- Examining how results on adults' competencies from PIAAC might be integrated into human capital accounting so as to produce "quality-adjusted" estimates.

- Identifying and reinforcing the structural links between human capital accounting and other economic entities in the SNA.

- Investigating potential possibilities for addressing more policy issues based on the human capital accounting exercise.

33. For more discussions on this issue, see Abraham (2010) and Fraumeni (2011). 


\section{REFERENCES}

Abraham, K. G. (2010), “Accounting for Investment in Formal Education”, Survey of Current Business, June 2010, 42-53.

Aghion, P. and P. Howitt (1998), Endogenous Growth Theory, MIT Press, Boston.

Ahlroth, S., A. Björklund and A. Forslund (1997), "The Output of the Swedish Education Sector", Review of Income \& Wealth, 43(1), 89-104.

Becker, G. S. (1964), Human Capital, Columbia University Press, New York.

Card, D. (2001), "Estimating the Return to Schooling: Progress on Some Persistent Econometric Problems", Econometrica 69, no. 5 (September): 1,127-1,160.

Christian, M. S. (2010), "Human Capital Accounting in the United States", 1964-2006, Survey of Current Business, June, 31-36.

Conrad, K. (1992), "Comment on 'Investment in Education and U.S. Economic Growth”, by D. W. Jorgenson and B. M. Fraumeni. Scandinavian Journal of Economics 94 (supplement): S71-S74.

Diewert, W. E. (1976), "Exact and superlative index numbers", Journal of Econometrics, Vol. 4, No. 2, $115-145$.

Dolan, P., T. Peasgood, and M. White (2008), "Do we really know what makes us happy? A review of the economic literature on the factors associated with subjective well-being", Journal of Economic Psychology, 29, 94-122.

Ederer, P., P. Schuller, and S. Willms (2007), Innovation at Work: The European Human Capital Index, The Lisbon Council Policy Brief, Volume 2, Number 3, Brussels.

Ederer, P., P. Schuller and S. Willms (2011), Human Capital Leading Indicators - How Europe's Regions and Cities Can Drive Growth and Foster Inclusion, The Lisbon Council, Brussels.

Eisner, R. (1985), “The total incomes system of accounts”, Survey of Current Business, 65(1), 24-48.

Engel, E. (1883), Der Werth des Menschen, Verlag von Leonhard Simion, Berlin.

Ervik, A. O., E. Holmøy and T. Hægeland (2003), “A Theory-Based Measure of the Output of the Education Sector”, Discussion Paper No. 353, Statistics Norway.

Farr, W. (1853), “Equitable taxation of property”, Journal of Royal Statistics, 16 (March issue), 145.

Fraumeni, B. M. (2008), "Human Capital: From Indicators and Indexes to Accounts", paper presented at the OECD workshop on "The Measurement of Human Capital" in Turin, Italy, 3-4, November. 
Fraumeni, B. M. (2009), “A Measurement Specialist's Perspective on Human Capital”, presentation at China Centre for Human Capital and Labour Market Research, Central University of Finance and Economics, Beijing, China, June 11.

Fraumeni, B. M. (2011a), "Human Capital Accounts: Choice of Rates and Construction of Volume Indices", National Bureau of Economic Research Working Paper No. 16895, March.

Graham, J. W. and R. H. Webb (1979), "Stocks and depreciation of human capital: New evidence from a present-value perspective". Review of Income and Wealth, 25 (2), 209-224.

Greaker, M., P. Løkkevik and M. A. Walle (2005), ’Utviklingen i den norske nasjonalformuen fra 1985 til 2004. Et eksempel på bærekraftig utvikling?" (Development of the Norwegian national wealth 19852004. An example of sustainable development?) Report 2005/13, Statistics Norway, Oslo.

Greaker, M. and G. Liu (2008), "Measuring the stock of human capital for Norway: A lifetime labour income approach", paper presented at the OECD workshop on "The Measurement of Human Capital' in Turin, Italy, 3-4 November.

Gu, W. and A. Wong (2008), "Human development and its contribution to the wealth accounts in Canada", paper presented at the OECD workshop on "The Measurement of Human Capital" in Turin, Italy, 34 , November.

Gu, W. and A. Wong (2009), "Human development and its contribution to the wealth accounts in Canada", paper presented at the International Symposium on Measuring Human Capital and Its Impact on Welfare and Growth, Beijing, China, 9-10, October.

Gu, W. and A. Wong (2010), "Estimates of Human Capital: The Lifetime Income Approach", Economic Analysis Research Paper Series, No. 062, Statistics Canada.

Jorgenson, D.W. (1963), “Capital Theory and Investment Behavior”, American Economic Review, 53(2): 247-259.

Jorgenson, D.W. (1967), “The Theory of Investment Behavior”, in The Determinants of Investment Behavior, Conference of the Universities-National Bureau of Economic Research, Columbia University Press, New York, NY.

Jorgenson, D.W. and B.M. Fraumeni (1989), "The Accumulation of Human and Non-Human Capital, 1948-1984”, in R.E. Lipsey and H.S. Tice (eds.), The Measurement of Savings, Investment, and Wealth, The University of Chicago Press, Chicago.

Jorgenson, D.W and B.M. Fraumeni (1992a), "The Output of Education Sector", in Z. Griliches (ed.) Output Measurement in the Service Sectors, The University of Chicago Press, Chicago.

Jorgenson, D.W and B.M. Fraumeni (1992b), "Investment in Education and U.S. Economic Growth", Scandinavian Journal of Economics, 94, Supplement, 51-70.

Jorgenson, D.W. and K. -Y. Yun (1990), “Tax Reform and U.S. Economic Growth”, Journal of Political Economy, 98: S151-193.

Jorgenson, D.W., M.S. Ho, and K.J. Stiroh (2005), Information Technology and the American Growth Resurgence, Volume 3, Productivity, Harvard University Press, Cambridge, MA. 
Kendrick, J. (1976), The Formation and Stocks of Total Capital, Columbia University Press, New York, N.Y.

Kyriacou, G. A. (1991), "Level and Growth Effects of Human Capital: A Cross-Country Study of the Convergence Hypothesis", Economic Research Reports 19-26, C. V. Starr Centre for Applied Economics, New York University.

Le, T., J. Gibson, and L. Oxley (2003), "Cost- and Income-based Measures of Human Capital”, Journal of Economic Surveys, 17(3), 271-307.

Le, T., J. Gibson, and L. Oxley (2006): "A Forward-Looking Measure of the Stock of Human Capital in New Zealand”, The Manchester School, Vol.74, No.5, 593-609.

Li, H., Y. Liang, B. M. Fraumeni, Z. Liu, and X. Wang (2010), "Human Capital in China", paper presented at the $31^{\text {st }}$ General Conference of The International Association for Research in Income and Wealth, St. Gallen, Switzerland, August 22-28.

Liu, G. and M. Greaker (2009), "Measuring the stock of human capital for Norway - A lifetime labour income approach", Documents, 2009/12, Statistics Norway.

Lucas, R. E. Jr. (1988), "On the mechanics of economic development”, Journal of Monetary Economics, $22(1), 3-42$.

Mincer, J. (1974), Schooling, Experience and Earnings, Columbia University Press, New York.

OECD (2001), The Well-being of Nations: The Role of Human and Social Capital, OECD Publishing, Paris.

OECD (2004), “2004 Data Collection on Education Systems - UOE data collection manual”, Paris.

OECD (2009), OECD Economic Outlook, Volume 2009/1, No. 85, OECD Publishing, Paris.

OECD (2010a), Improving Health and Social Cohesion through Education, OECD Publishing, Paris.

OECD (2010b), "The OECD Human Capital Project: Progress Report”, paper presented at the $31^{\text {st }}$ General Conference of The International Association for Research in Income and Wealth, St. Gallen, Switzerland, August 22-28.

O`Mahony, M. and P.A. Stevens (2004), "International Comparisons of Performance in the Provision of Public Services: Outcome Based Measures for Education", National Institute of Economic and Social Research, London, U.K.

Pearce, D. W. and G. D. Atkinson (1993), "Capital theory and the measurement of sustainable development: an indicator of weak sustainability", Ecological Economics, 8 (2), pp. 103-108. doi:10.1016/0921-8009(93)90039-9.

Petty, W. (1690), Political Arithmetic, reprinted in C. H. Hull (1899), The Economic Writings of Sir William Petty, Cambridge University Press, Cambridge.

Romer, P. M. (1986), “Increasing returns and long run growth”, Journal of Political Economy, 94 (5), 1002-1037. 
Romer, P. M. (1989), "Human capital and growth: theory and evidence", National Bureau of Economic Research Working Paper No. 3173.

Rosen, S. (1989), "Comment on 'The Accumulation of Human and Nonhuman Capital', by Dale W. Jorgenson and Barbara M. Fraumeni", in R. E. Lipsey and H. Stone Tice (eds.), The Measurement of Saving, Investment, and Wealth, University of Chicago Press, Chicago.

Ruta, G. and K. Hamilton (2007), "The capital approach to sustainability”, in Atkinson, G. et al. (eds.), Handbook of Sustainable Development, Edward Elgar Publishing, Inc.

Schleicher, A. (2008), "PIAAC: A New Strategy for Assessing Adult Competencies", International Review of Education, DOI 10.1007/s11159-008-9105-0.

Schreyer, P. (2010), "Towards Measuring the Volume Output of Education and Health Services - A Handbook", OECD Statistics Working Papers, 2010/2, Paris.

Shultz, T. W. (1961), "Investment in human capital”, American Economic Review, 51(1), 1-17.

Smith, A. (1776), An Inquiry into the Nature and Causes of the Wealth of Nations, Book 2. W. Strahan \& T. Cadell, London.

Stroombergen, A., D. Rose and G. Nana (2002), "Review of the Statistical Measurement of Human Capital", Statistics New Zealand.

UNECE (2009), Measuring Sustainable Development, Report of the Joint UNECE/OECD/Eurostat Working Group on Statistics for Sustainable Development, New York and Geneva.

UNESCO (2006), ISCED 1997- International Standard Classification of Education, Paris.

Wei, H. (2004), "Measuring the Stock of Human Capital for Australia”, Working Paper No. 2004/1, Australian Bureau of Statistics.

Wei, H. (2007), "Measuring Australia's Human Capital Development: The Role of Post-School Education and the Impact of Population Ageing", Statistical Journal of the IAOS 24, 183-191.

Wei, H. (2008), "Developments in the estimation of the value of human capital for Australia", paper presented at the OECD workshop on "The Measurement of Human Capital" in Turin, Italy, 3-4, November.

Weisbrod, B. A. (1961), “The valuation of human capital”, Journal of Political Economy, 69(5), 425-436.

World Bank (2006a), Where is the Wealth of Nations? The World Bank, Washington D.C.

World Bank (2006b), World Development Indicators 2006, The World Bank, Washington D.C. 